\title{
Vertical differentiation and trade among symmetric countries
}

\author{
P. M. Picard ${ }^{1,2} \cdot$ A. Tampieri ${ }^{1,3}$
}

Received: 11 September 2019 / Accepted: 4 July 2020 / Published online: 11 August 2020

(c) The Author(s) 2020

\begin{abstract}
We study a trade model with vertical product differentiation with many goods that are heterogeneous in cost and quality and produced in two quality versions. We discuss the composition of high- and low-quality goods in the workers' consumption baskets in countries between comparable countries. We show that a larger country population fosters its specialization in high-quality production while a higher country productivity leads to specialization in high quality production for all countries. Smaller trade costs foster specialization in high quality exports. We then discuss the effect of population heterogeneity on the consumption baskets and country specialization. Most of those results agree with existing empirical findings.
\end{abstract}

Keywords Vertical differentiation · Horizontal differentiation · Trade · Income heterogeneity

JEL Classification F12 $\cdot$ F16 $\cdot$ L11 $\cdot$ L15

The authors thank the Editor C. Arkolakis and two anonymous referees for helpful comments. They are also grateful to F. Etro, A. Fieler, W.-T. Hsu, K. Matsuyama, P. Neary, G. Ottaviano, J. Tharakan and J. Wooton for relevant suggestions. Errors are ours.

$凶 \quad$ A. Tampieri

alessandro.tampieri@unifi.it

P. M. Picard

pierre.picard@uni.lu

1 CREA/FDEF, University of Luxembourg, 6, rue Richard Coudenhove-Kalergi, 1359

Luxembourg City, Luxembourg

2 CORE, Université catholique de Louvain, Louvain-la-Neuve, Belgium

3 Department of Economics, University of Florence, Via delle Pandette 9, Florence 50127, Italy 


\section{Introduction}

There is substantial evidence that product quality matters in the trade patterns. In particular, it is now well documented that both the exports and imports of richer countries are biased towards more high quality goods (Schott 2004; Hummels and Klenow 2005). ${ }^{1}$ As a result more productive countries tend to specialize in the export of high quality goods. Similarly, it has been shown that lower barriers to trade fosters the specialization in high quality exports (Amiti and Khandelwal 2013, and Fan et al. 2015).

These empirical findings have prompted a recent theoretical literature on trade and quality. Yet, developments of the theory literature did not focus on the evidence that countries export the same goods to the same destination at very different quality levels. Indeed, there exists high variations in the export and import prices within the same narrow product category. For instance, de Lucio Fernández et al. (2016) show that Spanish firms charge a wide range of prices for the same CN8 product to the same destination market, suggesting a wide set of quality levels in Spanish exports to a same destination. Fontaine et al. (2020) also show an important price dispersion of French exports to a same destination. To the best of our knowledge, with the exception of Fieler (2012), no theory paper has investigated a general equilibrium framework where firms export same goods to same destinations at different quality levels.

We construct a new model of international trade in line with the traditional view of vertical differentiation. We introduce continuous sets of differentiated goods produced at a high and low quality. Goods are heterogeneous in their production costs and quality levels and are sold under perfect competition. Consumers purchase a single unit of each good in only one quality version. Preferences are non-homothetic and lead to income effect on consumption baskets of high and low quality goods: richer individuals buy goods of higher quality. As stated by Markusen (2013), “an area where per-capita income does play an important role is in the analysis of product quality. If a consumer is going to buy only one unit of a good or zero, then the quality demanded is likely to depend on per-capita income..." In this paper, we assume that income effects do not influence neither the number of goods nor the quantity of each good purchased by each consumer. Rather, we consider that they impact the quality of goods purchased. The study of such a framework is novel and important because it reproduces the fact that traded goods are versioned in different quality levels.

We discuss the international trade patterns of two similar countries hosting populations with homogeneous and heterogeneous incomes. In contrast with the previous literature studying North-South trade with asymmetric production functions for product quality, we consider countries with closely symmetric production capabilities. We first focus on countries with homogeneous populations and give the conditions under which the trade equilibrium exists. We further apply the model to the case of countries with heterogeneous income distributions. In contrast to the existing literature, this case encompasses the possibility of exporting of two quality versions of the same good between two trade partners.

\footnotetext{
${ }^{1}$ See also Verhoogen (2008), Khandelwal (2010), Hallak and Schott (2011), Crozet et al. (2012), among others.
} 
From our analysis, we can elicit several findings. First, our model allows to evaluate the effect of changes in population size. We find that, ceteris paribus, larger country population makes this country specialize in high-quality production and exports while the trading partner specializes into low quality exports. This is because, the larger country supplies more labor for the production of each product quality and variety, which drives down the relative prices of high quality goods. To the best of our knowledge, this result is not been investigated in the empirical literature. Second, we show that a higher country productivity fosters specialization in high quality export of both countries. The model with vertical differentiation therefore conforms to the empirical evidence cited above. For instance, using U.S. trade data, Schott (2004) finds that skill-abundant countries export vertically superior varieties, commanding higher prices. Similarly, Hummels and Klenow (2005) show that the richer U.S. trade partners export goods with higher prices. Verhoogen's (2008) and Iacovone and Javorcik's (2010) give empirical evidence about the export of higher quality versions from Mexico to richer countries (like the US). Hallak and Schott's (2011) show that poorer economies export higher quality goods to richer markets. Fieler (2012) shows that quality levels (measured by unit prices) rise with importers' per-capita incomes. The implications of changes in productivity also match the Linder (1961) according to which richer countries trade more high quality goods.

We also discuss the effect of trade costs in this model and analyze their effect on trade in the presence of vertical differentiation. We find that, when trade costs are not too high, trade integration fosters the specialization in high quality goods in both countries, which also conforms to the evidence cited above. In particular, Amiti and Khandelwal (2013) and Fan et al. (2015) show that a fall in tariff entices producing countries to raise the quality of their exports.

We finally consider a trade economy with skill or income heterogeneity within each population. We show that an increase in the productivity of a domestic skill group benefits this group as well as all foreign ones, while it harms all other domestic skill groups. While the domestic country specializes further in the export of high quality goods, the foreign country also specializes in high quality exports only if the domestic skill group is large enough. This result can be related to the literature about skill bias technological changes that have favored high skilled workers (see Acemoglu and Autor 2011 for a review). In our context, such changes foster specialization in high quality exports, enhance trade values and benefit high skilled workers at the expense of low skill ones. To the best of our knowledge, the above results on trade and vertical differentiation and the connections between trade patterns and product quality are new in the literature on product quality and trade.

Related literature The paper relates to several strands of the economic theory literature. We here shortly review the related literature and apologize for potential omissions.

First, this paper closely relates to the general equilibrium studies of vertical differentiation with trade. In the early theory literature, product quality was seen as a feature of vertical differentiation where each good is versioned under different quality levels and 
consumed in a single unit. ${ }^{2}$ Importantly, vertical differentiation implies that, at same unit price, consumers rank of various quality versions of each good in the same way. Accordingly, consumers have common rankings for Breitling over Swatch watches, Iphone over Blackberry, etc. Such definition typically applies to durable goods like cars, houses, watches, etc. but also to non-durable goods like clothing and drinks. This view has been applied to trade in a small set of important contributions (Flam and Helpman 1987; Stokey 1991; Matsuyama 2000).

The present contribution significantly differs from this early strand of literature as follows. First, while Flam and Helpman (1987) and followers focus on an endogenous and 'continuous quality spectrum' of the same good, this paper considers an exogenous set of horizontally differentiated goods with only two quality levels (which limits the dimensionality of the problem). Second, this paper considers trade partners with comparable conditions rather than the typical North-South situation where the South suffers from an exogenous production disadvantage. Production conditions and product characteristics are here closely symmetric across countries. Third, this paper follows Armington's (1969) assumption by which countries produce horizontally differentiated goods and which has been followed in a large trade literature (Krugman 1981). While the above contributions assume that all quality versions can be produced anywhere, all versions of a same good are produced in the same country in this paper: that is, both premium and lower quality sparkling wines are produced in Champagne region (see 'échelle des grands crus'), higher and lower quality watches in Switzerland (Breitling v/s Swatch), etc.. This setting allows us to discuss a less extreme quality composition of trade flows where exports include mixes of high and low quality goods in all trade directions.

Our model shares important features with the trade models discussed in Matsuyama (2000) and Fieler (2012): continuum of varieties, perfect competition in each industry, one unit of good purchased for each variety, non-homothetic preferences and absence of substitution among varieties. Matsuyama (2000) however studies a model with a unique quality level in each variety and lexicographic preferences for the varieties. He also focuses on the asymmetric situation where the North country has an absolute advantage and produces the higher quality goods. By contrast, this paper studies the choice of two quality levels in each variety and focuses on a more symmetric situation where both countries have balanced productivities. ${ }^{3}$ As in this paper, Fieler (2012) discusses the production of multiple quality levels for each traded good. In contrast with this paper, she assumes that the production technology of quality is the same for all goods. Because our framework is simpler and focuses on closely symmetric countries, it permits to discuss the existence and stability of trade equilibria and to explain the impact of population size, population income heterogeneity and productivity differences on the trade of high and low quality goods.

It must be noted that the study of those trade models with unit-purchased goods and vertical differentiation is generally limited to perfect competition. By contrast, Tarasov $(2009,2012)$ studies trade under monopolistic competition in the same unit-purchase

\footnotetext{
2 See Mussa and Rosen (1978); Gabszewicz and Thisse (1979); Shaked and Sutton (1982). More recent contributions are Gabszewicz and Wauthy (2003), Tanaka (2001) and Jaimovich (2020).

3 To highlight the contrast with Matsuyama (2000), Sect. 5 presents a short extension with comparative advantages between countries.
} 
preference model without vertical differentiation. However, embedding both quality issues and vertical differentiation in such framework still poses serious analytical issues.

Because of the focus on intra-industry trade (Krugman 1981), the most recent trade literature has moved to the study of horizontal differentiation models with divisible goods and, for the purpose of discussing product quality, has augmented them with idiosyncratic demand shifters. However, in this approach, each good is declined in a unique quality version so that models are unable to explain how consumers switch from lower to higher quality products and to discuss goods for which consumers have common quality rankings. In addition, those models do not catch income effects because consumption is proportional to income, so that richer individuals and/or countries do not have higher consumption share of high-quality products. Among the relevant contributions, Jaimovich and Merella $(2012,2015)$ mix an upper-tier homothetic CES preferences with a lower-tier subutility function that combines quality levels and log of quantity. As in this paper, they feature higher quality consumption by the richer country and highlight that a higher global productivity increases the production and consumption of high quality goods across borders (Linder hypothesis). Eaton and Fieler (2017) include a lower-tier CES subutility function that combines quantity and quality as complementary attributes. Despite non-homothetic intricacies introduced by quality, they obtain an interesting homothetic-like gravity equation. Finally, Matsuyama (2015) expands the CES preferences to the more general Hanoch preferences with sectors of heterogeneous income elasticity. By considering that higher quality goods belong to sectors producing goods with higher income elasticity, he shows that richer countries becomes a net-exporter of high quality goods.

Another strategy is to exploit the aggregation properties of random utility models where unit-purchase choices combine in continuous aggregates. In particular, Fajgelbaum et al. 2011, 2015 and Dingel (2017) use a random utility model to study the impact of income on the quality of traded goods. Finally, trade and product quality also have been studied in the class of models with quadratic-linear preferences over divisible goods (Picard and Okubo 2012). Di Comite et al. (2014) propose to reconcile vertical and horizontal differentiation by considering consumers with two dimensional taste heterogeneity (on demand intercepts and slopes). In contrast to this paper, all the above models however assume a single quality version for each good.

Finally, because it considers non-homothetic preferences, the present paper remotedly relates to the literature on competition and trade with demand based on non-homothetic preferences. ${ }^{4}$ The implications on trade of non-homothetic preferences have been examined in Behrens and Murata (2012), Sauré (2012), Behrens et al. (2014), Feenstra and Romalis (2014), Simonovska (2015), Bertoletti et al. (2018), Foellmi et al. (2018) and Matsuyama (2018), among others. In this strand, Matsuyama

\footnotetext{
4 Recently, there has been important developments in the literature on non-homothetic preferences, see Foellmi and Zweimueller (2006), Behrens and Murata (2007), Bond et al. (2011), Zhelobodko et al. (2012), Bertoletti and Etro (2016, 2017), Parenti et al. (2017), and Dhingra and Morrow (2019), among others. In particular, Bertoletti and Etro (2017) analyze monopolistic competition with additively separable indirect utilities. They also introduce quality in a closed economy, where more productive firms produce higher quality goods and sell it at a higher price. In line with the Linder hypothesis, higher income drives specialization in the production of high-quality goods. Compared to this paper, they assume that each variety is sold at a single quality and do not allow for the purchase of goods versioned at different quality levels.
} 
(2018) analyze the effects of income elasticity differences on sectorial compositions, technological innovation and trade patterns. Finally, Arkolakis et al. (2019) depart from the CES utility to analyze the gains from trade in economies with variable mark-ups. Their general demand system also embeds the non-homothetic case.

The remainder of the paper is organized as follows. Section 2 describes the model. Sections 3 and 4 discuss trade with within-country homogeneous and heterogeneous population. Section 5 discusses possible limitations of the model. Section 6 concludes.

\section{Model}

We consider two trading countries (domestic and foreign) respectively populated by the masses $M$ and $M^{*}$ of individuals, where the asterisk denotes foreign variables. For the sake of exposition, we firstly assume that individuals are have individual labor unit endowment (skills) $s$ and $s^{*}$ with cumulative distribution functions $G$ and $G^{*}$.

Following Armington (1969), domestic and foreign goods are differentiated and produced in a single country. Hence, each country is endowed with an exogenous set $\mathcal{Z} \supset \mathbb{R}$ of horizontally differentiated goods with mass $Z>0$. The world mass of goods is equal to $2 Z$. By convention, goods are addressed by the indexes $z$ and $z^{*} \in \mathcal{Z}$ in both domestic and foreign product sets, respectively. We follow the vertical differentiation literature and consider that each good can be produced in different quality versions. To simplify the discussion, we consider only two quality versions $i \in\{H, L\}$, the higher quality $H$ being more expensive to produce than the lower quality $L$. That is, a unit of good $z$ requires respectively $a_{L}(z)$ and $a_{H}(z)$ domestic labor units for the production of its low and high quality version with $a_{H}(z)>a_{L}(z)>0$. Perfect competition entails that the prices of a home good $z$ and foreign $\operatorname{good} z^{*}$ are equal to their unit costs:

$$
p_{i}(z)=a_{i}(z) w \text { and } p_{i}^{*}\left(z^{*}\right)=a_{i}\left(z^{*}\right) w^{*}, \quad i \in\{H, L\}
$$

where $w$ and $w^{*}$ are the domestic and foreign factor price per labor unit.

Following the vertical differentiation literature, we consider that each individual consumes a unit of every good at a single quality version. ${ }^{5}$ Her decisions over consuming the quality version $i$ of domestic and foreign goods $z$ and $z^{*}$ are given by $x_{i}(z)$ and $x_{i}^{*}(z) \in\{0,1\}$ subject to the unit purchase conditions $x_{H}(z)+x_{L}(z)=1$ and $x_{H}^{*}\left(z^{*}\right)+x_{L}^{*}\left(z^{*}\right)=1$. The consumer is endowed with the utility function

$$
U=\int_{\mathcal{Z}}\left(\sum_{i=H, L} b_{i}(z) x_{i}(z)\right) \mathrm{d} z+\int_{\mathcal{Z}}\left(\sum_{i=H, L} b_{i}\left(z^{*}\right) x_{i}^{*}\left(z^{*}\right)\right) \mathrm{d} z^{*},
$$

where $b_{H}(z)$ and $b_{L}(z)$ are the utility of each quality version of domestic good $z$, a higher quality providing more utility than the lower one, $b_{H}(z)>b_{L}(z)>0$.

\footnotetext{
5 This assumption is standard in the tradition of vertically differentiated models, both in general equilibrium (Flam and Helpman 1987; Stokey 1991; Matsuyama 2000; Fieler 2012) and partial equilibrium (Sutton, 2007, Verhoogen 2008; Khandelwal 2010).
} 
The symmetric definition applies for the utility of foreign goods. Hence, the profile $b_{i}(z)$ measures the consumer-specific tastes for the goods with quality $i=H, L$. For conciseness, those parameters are called the "quality" of versions $H$ and $L$ of goods. The consumer chooses the quality profiles $x_{i}$ and $x_{i}^{*}$ that maximizes her utility subject to her budget constraint

$$
\int_{\mathcal{Z}}\left(\sum_{i=H, L} p_{i}(z) x_{i}(z)\right) \mathrm{d} z+\int_{\mathcal{Z}}\left(\sum_{i=H, L} p_{i}^{*}\left(z^{*}\right) x_{i}^{*}\left(z^{*}\right)\right) \mathrm{d} z^{*}=w s .
$$

where $p_{i}(z)$ and $p_{i}^{*}(z)$ are the prices of home and foreign goods with label $z$. Necessary and sufficient conditions for the optimal choice impose that, for each home good $z \in \mathcal{Z}$, there exists a positive scalar $\mu$ such that she buys the home high quality $H$ if

$$
b_{H}(z)-\frac{1}{\mu} p_{H}(z) \geq b_{L}(z)-\frac{1}{\mu} p_{L}(z),
$$

and the home low quality $L$ otherwise, the same applying for the purchase of foreign goods. The scalar $\mu$ is equal to the inverse of the Lagrange multiplier of the budget constraint. It measures the inverse of the marginal utility of income and is a function of the individual's skill $s$ (see below). Throughout the text, we will shortly refer to it as the "inverse marginal utility". As shown in the left hand side condition, a consumer therefore compares the utility brought by high and low quality versions with their prices weighted by their marginal utility. She prefers the higher quality good if it has higher quality and lower price. Plugging the prices (1), we get

$$
\frac{\mu}{w} \geq \frac{a_{H}(z)-a_{L}(z)}{b_{H}(z)-b_{L}(z)}
$$

She purchases the higher quality version of the goods for which her inverse marginal utility is higher than the right hand side of this inequality. The set of high-quality domestic goods consumed by the domestic individuals with $\mu$ is then given by

$$
\mathcal{H}\left(\frac{\mu}{w}\right) \equiv\left\{z \in \mathcal{Z}: \frac{\mu}{w} \geq \ell(z)\right\}
$$

where $\ell: \mathcal{Z} \rightarrow \mathbb{R}^{+}$,

$$
\ell(z) \equiv \frac{a_{H}(z)-a_{L}(z)}{b_{H}(z)-b_{L}(z)}
$$

The function $\ell(z)$ measures the home labor input that each additional unit of utility (or quality) requires in the process of upgrading good $z$. For brevity, we call it the home "per-quality input". What matters in the choice of quality version of a good is the balance between this per-quality input $\ell$ and the consumer's inverse marginal utility $\mu$ relative to the wage $w$ in the production country. The higher the marginal utility and the lower the wage, the wider the set of high-quality goods consumed. 

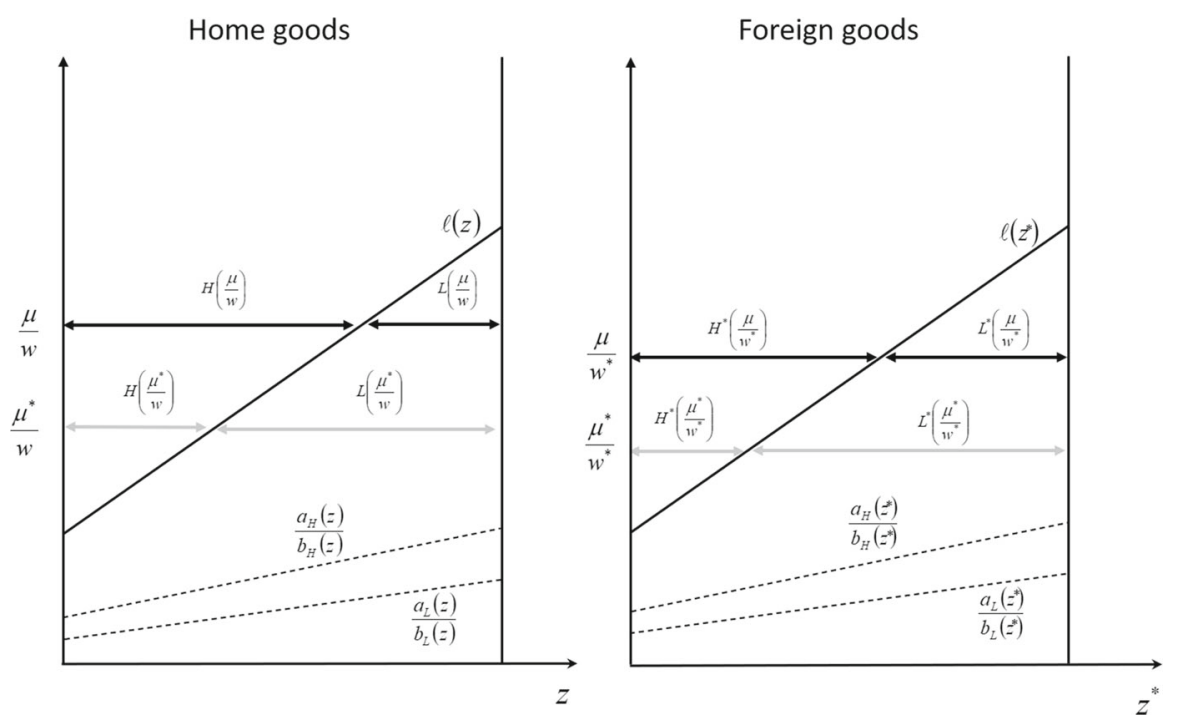

Fig. 1 Input per quality and choice of goods' quality. Note The left hand panel compares the per-quality input $\ell(z)$ of each domestic good $z \in \mathcal{Z}$ to $\mu / w$ and $\mu^{*} / w$ of home and foreign consumers. The sets of home high-quality goods consumed by those consumers are respectively denoted by $H(\mu / w)$ and $H\left(\mu^{*} / w\right)$. The sets of low-quality goods are denoted by $L(\mu / w)$ and $L\left(\mu^{*} / w\right)$. The right hand panel presents the choice for foreign goods $z^{*} \in \mathcal{Z}$

Likewise, it can be shown that the set of high-quality imports consumed by this domestic individual is given by $\mathcal{H}^{*}\left(\mu / w^{*}\right)=\left\{z^{*} \in \mathcal{Z}: \mu / w^{*} \geq \ell\left(z^{*}\right)\right\}$. Consumption of high-quality imports depends on the consumer's inverse marginal relative to exporting country's wage $w^{*}$. Given that the sets of goods are exogenous, the set of low-quality purchases $\mathcal{L}$ and $\mathcal{L}^{*}$ are the complements $\mathcal{L} \equiv \mathcal{Z} \backslash \mathcal{H}$ and $\mathcal{L}^{*} \equiv \mathcal{Z}^{*} \backslash \mathcal{H}^{*}$ where the sign $\backslash$ denotes the operator for set difference.

Foreign consumers are endowed with the same utility function but have income $w^{*} s^{*}$. By the same argument, they get an inverse marginal utility of income denoted by $\mu^{*}$ and purchase the sets of home and foreign high-quality goods, $\mathcal{H}\left(\mu^{*} / w\right)$ and $\mathcal{H}^{*}\left(\mu^{*} / w^{*}\right)$, where $\mathcal{H}$ and $\mathcal{H}^{*}$ have same definitions as above.

The left and right panels of Fig. 1 depict the per-quality input of goods produced respectively at home and abroad. A domestic individual with inverse marginal utility $\mu$ consumes the set of high-quality domestic goods, $\mathcal{H}(\mu / w)$, and the complementary set of low-quality domestic goods, $\mathcal{L}(\mu / w)$ (intersection of horizontal black line at $\mu / w$ with the curve $\ell(z)$ in the left panel). She also consumes the sets of high and lowquality imports, $\mathcal{H}^{*}\left(\mu / w^{*}\right)$ and $\mathcal{L}^{*}\left(\mu / w^{*}\right)$ (intersection of horizontal black curves with $\ell\left(z^{*}\right)$ in the right panel). Similarly, a foreign consumer with inverse marginal utility $\mu^{*}$ consumes the sets of high- and low-quality foreign goods, $\mathcal{H}^{*}\left(\mu^{*} / w^{*}\right)$ and $\mathcal{L}^{*}\left(\mu^{*} / w^{*}\right)$ (intersection with gray line with $\ell\left(z^{*}\right)$, right panel), and imports from sets of domestic high- and low-quality goods, $\mathcal{H}\left(\mu^{*} / w\right)$ and $\mathcal{L}\left(\mu^{*} / w\right)$ (intersection with gray line with $\ell(z)$, left panel). 
As shown in Fig. 1, we can rank the goods so that the per-quality input $\ell$ is a strictly increasing function. We then make two technical assumptions. First, we assume that every individual buys a mix of high and low qualities. That is, all domestic individuals with labor unit endowment $s$ obtain values of $\mu / w$ and $\mu / w^{*}$ that lie in the image set of $\ell$. This guarantees that the identities $\mu / w=\ell(z)$ and $\mu / w^{*}=\ell\left(z^{*}\right)$ have unique interior solutions for $z$ and $z^{*}$. The same assumption applies for foreign individuals. Second, as mentioned above, we assume that the consumer purchases each good at one or another quality: $x_{H}(z)+x_{L}(z)=1$. This is a standard assumption in vertical differentiation literature and labeled as "full market coverage". 6 It is also imposed in most horizontal differentiation trade models where consumers purchase all goods (e.g. under Cobb-Douglas or CES preferences). ${ }^{7}$ In our context, the last assumption implies two conditions. First, if the domestic consumer prefers a highquality to a low-quality domestic $\operatorname{good} z(\mu / w \geq \ell(z))$, she should also be willing to buy it $\left(x_{H}(z)=1\right)$. One can check that the consumer buys a high quality good if $\mu \geq p_{H}(z) / b_{H}(z)$, or equivalently, $\mu / w \geq a_{H}(z) / b_{H}(z)$. Using this, the above condition becomes $\ell \geq a_{H} / b_{H}$. That is, the image set of $\ell$ lies above the schedules $a_{H} / b_{H}$ as shown by the top dashed line in Fig. 1 . Second, if the domestic consumer prefers a low-quality to a high-quality domestic good, she should be able to buy it. One can similarly check that is implies $\mu / w \geq a_{L}(z) / b_{L}(z)$. A sufficient condition is that $\mu / w \geq \max _{z} a_{L}(z) / b_{L}(z)$. This is shown by the bottom dashed lines in Fig. 1 . There exists infinitely many primitive functions $\left(a_{H}, a_{L}, b_{H}, b_{L}\right)$ that meet this condition. It will be met for all the examples provided in the sequel.

The consumers' budget constraints can be written as

$$
w E\left(\frac{\mu}{w}\right)+w^{*} E\left(\frac{\mu}{w^{*}}\right)=w s \text { and } w^{*} E\left(\frac{\mu^{*}}{w^{*}}\right)+w E\left(\frac{\mu^{*}}{w}\right)=w^{*} s^{*},
$$

where we define

$$
E(y) \equiv \int_{\mathcal{H}(y)} a_{H}(z) \mathrm{d} z+\int_{\mathcal{L}(y)} a_{L}(z) \mathrm{d} z
$$

We use the symbol $y$ to refer to the instances of inverse marginal utility $\mu, \mu^{*}, \mu / w$ and $\mu^{*} / w$. Each term in the left hand sides of (4) reflects the consumer's expenditure on home and foreign goods. By contrast, the function $E(y)$ measures such expenditures in terms of the labor input. We call $E(y)$ "real expenditure function" as it expresses the expenditure using labor in the production country as numéraire. Since $\mathcal{H}(y)$ expands with larger $y$, real expenditure functions increase with it so that $E^{\prime}(y)>0$. Differentiating the domestic consumer's budget constraint in (4), we get

$$
\frac{\mathrm{d} \mu}{\mathrm{d} s}=\frac{w}{E^{\prime}(\mu / w)+E^{\prime}\left(\mu / w^{*}\right)}>0
$$

\footnotetext{
6 See Crampes and Hollander (1995), Boom (1995), Ecchia and Lambertini (1997), Maxwell (1998) and Wang (2003), among others.

7 Alternatively, Tarasov (2009) and Foellmi et al. (2018) consider "0-1 preferences", where consumers purchase one or zero unit of each good. They, however, do not model quality.
} 
Table 1 Four model examples

\begin{tabular}{|c|c|c|c|c|}
\hline & \multicolumn{2}{|l|}{ Linear expenditure } & \multicolumn{2}{|l|}{ Isoelastic expenditure } \\
\hline & (a) & (b) & (a) & (b) \\
\hline \multicolumn{5}{|l|}{ Assumptions: } \\
\hline $\mathcal{Z}$ & {$\left[1, \kappa^{1 / 2}\right]$} & {$[\underline{z}, \bar{z})$} & {$[0,1]$} & {$[0,1]$} \\
\hline$a_{H}(z)$ & $4 z$ & $1+\bar{z}^{2}(\bar{z}-z)^{-2}$ & $2 z$ & $1+\alpha(1-z)^{-\alpha-1}$ \\
\hline$a_{L}(z)$ & $2 z$ & 1 & $z$ & 1 \\
\hline$b_{H}(z)$ & $2(1+\gamma) z^{-1}$ & $1+(\bar{z}-z)^{-1}$ & $(1+\beta) z\left(\frac{1}{2}+\frac{z^{2}}{2}\right)^{-\frac{1}{\alpha}}$ & $1+\alpha(1-z)^{-\alpha}$ \\
\hline$b_{L}(z)$ & $2 \gamma z^{-1}$ & 1 & $\beta z\left(\frac{1}{2}+\frac{z^{2}}{2}\right)^{-\frac{1}{\alpha}}$ & 1 \\
\hline Restrictions: & $\begin{array}{l}\kappa, \gamma>1 \\
\mu / w \geq \kappa /(1+\gamma)\end{array}$ & $\begin{array}{l}0<\underline{z}<\bar{z} \\
\mu / w \geq 1\end{array}$ & $\begin{array}{l}\alpha, \beta>1 \\
\mu / w \geq 1 / \beta\end{array}$ & $\alpha>1$ \\
\hline $\begin{array}{l}\text { per-quality input: } \\
\ell(z)\end{array}$ & $z^{2}$ & $\bar{z}^{2} /(\bar{z}-z)$ & $\left(1 / 2+z^{2} / 2\right)^{1 / \alpha}$ & $(1-z)^{-1}$ \\
\hline \multicolumn{5}{|l|}{ Real expenditure: } \\
\hline$E(y)$ & $y+\kappa-2$ & $y-\varsigma$ & $y^{\alpha}$ & $y^{\alpha}$ \\
\hline$d \ln E(y) / d \ln y$ & $y /(y+\kappa-2)$ & $\begin{array}{l}y /(y-\varsigma) \\
\varsigma=\frac{z(2 \bar{z}-\underline{z})}{(\bar{z}-\underline{z})}>0\end{array}$ & $\alpha$ & $\alpha$ \\
\hline \multicolumn{5}{|l|}{$\begin{array}{l}\text { Indirect utility } \\
\text { (up to constant) }\end{array}$} \\
\hline$V(y)$ & $\ln y$ & $\ln y$ & $\frac{\alpha \beta}{\alpha-1} y^{\alpha-1}$ & $\left(\frac{\alpha}{\alpha-1} y^{\alpha}-1\right) / y$ \\
\hline \multicolumn{5}{|c|}{ Number of $\mathrm{H}$ goods } \\
\hline$H(y)$ & $y^{1 / 2}-1$ & $\bar{z}^{2}(1 / \bar{z}-1 / y)-\underline{z}$ & $\left(2 y^{\alpha}-1\right)^{1 / 2}$ & $1-1 / y$ \\
\hline$v(y)$ & $\frac{1}{2} y^{1 / 2} /\left(y^{1 / 2}-1\right)$ & $1 /\left[y(\bar{z}-\underline{z}) / \bar{z}^{2}-1\right.$ & ]$\alpha y^{\alpha} /\left(2 y^{\alpha}-1\right)$ & $1 /(y-1)$ \\
\hline
\end{tabular}

The same argument applies for a foreign individual. As a consequence, the inverse marginal utilities are increasing functions of each individuals' labor endowment: $\mathrm{d} \mu / \mathrm{d} s>0$ and $\mathrm{d} \mu^{*} / \mathrm{d} s^{*}>0$.

There exist infinitely many profiles of input and preference primitives $\left(a_{H}, a_{L}\right.$, $b_{H}, b_{L}$ ) that fit the conditions of the model. Table 1 presents four examples that help illustrating the model along the text. In particular, they yield real expenditure functions $E$ that are equal to either power (isoelastic) or linear functions (see computations in "Appendix A"). In the examples labelled by (a), the cost of a product linearly increases with its "address" $z$ and its utility decreases with it. In other words, more costly products add lower utility increments to consumers. An interpretation is that goods with low $z$ consist of affordable necessities and those with high $z$ are luxury goods. The cost and utility of high and low quality versions are maintained in constant proportions along the product support. Importantly, upgrades of more costly products also bring lower utility increments. As a result, high cost goods tend to be purchased at the lower quality level. 
The profiles in the examples labelled by (b) have more involved structures but impose weaker restrictions the parameter sets supporting an equilibrium. In those examples, for simplicity, all low quality versions have the same cost and provide the same utility to consumers. By contrast, high quality goods have cost and utility functions that rise with their product "address" $z$ and tend to infinity for $z \rightarrow \bar{z}$. It can be seen that the utility increment from upgrading the quality of a good also rises with $z$ but at a slower pace than the associated cost increment. Therefore, in those examples, the high quality version of the good with the highest address $\bar{z}$ is unattractive and never purchased for any parameter set. This property assures that some goods are purchased at low quality levels, which helps fulfilling the restrictions for an equilibrium and acts as the well-known Inada condition.

It is important to note that those examples are chosen for their simplicity and just illustrate a much larger class of primitives having the same properties. Indeed, to obtain each example we impose the restriction of real expenditure $E(y)=y^{\alpha}$ or $E(y)=y+$ cst on the functional vector space $\left(a_{H}, a_{L}, b_{H}, b_{L}\right) \in(\mathcal{C}(\mathcal{Z}))^{4}$, where $\mathcal{C}(\mathcal{Z})$ is the space of real continuous functions on the real support $\mathcal{Z}$. This leaves a three dimensional space $(\mathcal{C}(\mathcal{Z}))^{3}$ in which to find primitive candidates that satisfy monotone input-per-quality and the two above assumptions. ${ }^{8}$ Some class of primitive like in the last example with linear real expenditure apply on less restrictive sets of parameter space.

Labor market clearing conditions close the model. One such condition is satisfied by Walras law. The remaining condition is equivalent to the trade balance condition, which equates the value of domestic exports to that of imports. Using real expenditures, this can be written as

$$
M \int w^{*} E\left(\frac{\mu(s)}{w^{*}}\right) \mathrm{d} G(s)=M^{*} \int w E\left(\frac{\mu^{*}\left(s^{*}\right)}{w}\right) \mathrm{d} G^{*}\left(s^{*}\right) .
$$

This identity determines the relative factor price $w / w^{*}$. Normalizing the foreign factor price to unity, the term of trade is given by $w$, the domestic price of labor.

To sum up, a trade equilibrium is defined by the profiles of competitive prices $\left(p_{i}, p_{i}^{*}\right)$ (condition (2)), the profiles of inverse marginal utility $\left(\mu, \mu^{*}\right)$ that match individuals' optimal consumption choices at given prices (condition (4)) and the scalar relative factor price $w$ that balances trade (condition (7)). Since prices are directly derived from factor prices, it is sufficient to check conditions (4) and (7). This nonlinear system of equations can be studied only in particular settings.

We first consider populations being homogeneous in their labor endowment.

\section{Homogeneous populations}

In this section we consider countries with homogeneous populations in the sense that home individuals have the same labor endowment $s$ and foreigners the same $s^{*} \cdot{ }^{9}$ Note

\footnotetext{
8 Technically, there always exists a vector of functions $\varepsilon=\left(\varepsilon_{1}, \varepsilon_{2}, \varepsilon_{3}, \varepsilon_{4}\right) \in(\mathcal{C}(\mathcal{Z}))^{4}, \varepsilon \neq 0$, such that $\left(a_{H}+\varepsilon_{1}, a_{L}+\varepsilon_{2}, b_{H}+\varepsilon_{3}, b_{L}+\varepsilon_{4}\right)$ satisfies the desired restriction on real expenditure.

9 That is, the distribution functions $G$ and $G^{*}$ degenerate on single atoms at $s$ and $s^{*}$.
} 
Table 2 Four model examples: equilibrium conditions and values

\begin{tabular}{llllll}
\hline & \multicolumn{2}{l}{ Linear expenditure } & & \multicolumn{2}{l}{ Isoelastic expenditure } \\
\cline { 2 - 3 } & (a) & (b) & & (a) & (b) \\
\hline Equilibrium conditions & $s \in[2 \kappa-2,4 \kappa-4]$ & $s \in[2(\bar{z}-\underline{z}), \infty)$ & & $s \in[1,2]$ & $s \in[2, \infty)$ \\
& $\kappa \leq 1+\gamma$ & $\bar{z}^{2}>(\bar{z}-\underline{z})$ & & $\beta^{\alpha} \geq 2$ & \\
Equilibrium values & & & & $\left(s_{k} / 2\right)^{1 / \alpha}$ & $\left(s_{k} / 2\right)^{1 / \alpha}$ \\
$\mu_{k}^{0}$ & $s_{k} / 2+2-\kappa$ & $s_{k} / 2+\varsigma$ & & $\frac{\alpha s_{k}}{2\left(s_{k}-1\right)}$ & $\frac{1}{\left(s_{k} / 2\right)^{1 / \alpha}-1}$ \\
$v\left(\mu_{k}^{0}\right)$ & $\frac{\frac{1}{2}\left(s_{k} / 2+2-\kappa\right)^{1 / 2}}{\left(s_{k} / 2+2-\kappa\right)^{1 / 2}-1}$ & $\bar{z}^{2}\left[\frac{1}{\bar{z}}-\frac{1}{\left(s_{k} / 2+\varsigma\right)}\right]-\underline{z}$ & & & \\
\hline
\end{tabular}

that, given homogeneous populations, $s$ and $s^{*}$ are equivalent to the domestic and foreign country productivity, respectively. In this section, we will thus refer to $s$ as "productivity". In this paper, we focus on similar countries so that we study the impact of small differences in productivity $\left(s, s^{*}\right)$ and population sizes $\left(M, M^{*}\right)$.

The trade equilibrium satisfies the following conditions:

$$
\begin{aligned}
s & =E\left(\frac{\mu}{w}\right)+\frac{1}{w} E(\mu), \\
s^{*} & =E\left(\mu^{*}\right)+w E\left(\frac{\mu^{*}}{w}\right), \\
m E(\mu) & =w E\left(\frac{\mu^{*}}{w}\right) .
\end{aligned}
$$

where $m$ denotes $M / M^{*}$. In the absence of effects on relative prices, consumers in a more productive country buy higher-quality products. Indeed, for a given $w$, $\mu$ increases as domestic productivity $s$ rises so that domestic consumers purchase more of all high-quality goods. The issue is about how relative prices impact this process. Under such general preference specification, equilibria may fail to be stable (Amano's, 1968). In what follows, we restrict our attention to stable symmetric trade equilibria. The trade equilibrium is stable if any small temporary shocks in population and productivity lead back to the symmetric configuration.

When countries are fully symmetric $\left(s / s^{*}=m=1\right)$, the trade equilibrium is a symmetric configuration where $w=w^{0} \equiv 1, \mu=\mu^{*} \equiv \mu^{0}$ and $s=2 E\left(\mu^{0}\right)$. Our above assumptions impose two restrictions for such a trade equilibrium to exist. The first restriction imposes that the image set of $\ell$ must include $\mu^{0}$. It can be shown that this is equivalent to the condition: $\int_{\mathcal{Z}} a_{L}(z) \mathrm{d} z \leq s / 2 \leq \int_{\mathcal{Z}} a_{H}(z) \mathrm{d} z$. The second restriction requires that the image set of $\ell$ lies above the schedules $a_{H} / b_{H}$ and $\mu / w$ above the schedule $a_{L} / b_{L}$. Those conditions can be satisfied for many classes of primitives $a_{i}$ and $b_{i}$. The first row of Table 2 illustrates the point with the examples presented in Table 1 (see "Appendix B"). In examples (b), equilibrium conditions impose that productivity is high enough for workers to be able to purchase all goods. In addition to this, equilibrium conditions in examples (a) impose an upper bound on productivity to discard the potential satiation of consumers. 
We are now equipped to study the impact of small discrepancies in domestic population $\tilde{m}=\mathrm{d} m / m>0$ and productivity $\tilde{s}=\mathrm{d} s / s>0$ on the consumption of high and low quality goods. Totally differentiating the above system of equations around the symmetric equilibrium yields the linear system

$$
\begin{aligned}
2 \widetilde{s} & =2 \eta \tilde{\mu}-(1+\eta) \widetilde{w}, \\
0 & =2 \eta \tilde{\mu}^{*}+(1-\eta) \widetilde{w}, \\
\tilde{m}+\eta \tilde{\mu} & =\widetilde{w}+\eta\left(\tilde{\mu}^{*}-\widetilde{w}\right),
\end{aligned}
$$

where $\tilde{x}=\mathrm{d} x / x$ denotes the relative difference in the variable $x$ and where

$$
\eta \equiv\left[\frac{\mathrm{d} \ln E(y)}{\mathrm{d} \ln y}\right]_{y=\mu^{0}}>0,
$$

measures the elasticity of real expenditure with respect to the inverse marginal utility at the symmetric equilibrium. Since $\mu^{0}=E^{-1}(s / 2)$, the elasticity of expenditure is exogenously given by the economic parameters.

The above equilibrium is expressed in terms of inverse marginal utility rather than demand and real expenditure. Equations (11)-(13) allow us to discuss the discrepancies in consumption of high quality goods around the symmetric equilibrium. Larger inverse marginal utilities $\mu$ and $\mu^{*}$ are associated with positive relative differences $\tilde{\mu}$ and $\tilde{\mu}^{*}$, while a larger relative factor price $w$ is associated with a positive relative difference $\widetilde{w}$. The domestic consumers' set of high-quality local goods $\mathcal{H}(\mu / w)$ expands with larger $\mu$ and smaller $w$; that is, if $\tilde{\mu}-\widetilde{w}>0$. Their set of high-quality imports $\mathcal{H}^{*}(\mu)$ expands with their inverse marginal utility $\mu$ or, equivalently, if $\widetilde{\mu}>0$. Equation (11) gives the domestic consumption response to relative factor price discrepancies. Equation (12) expresses the foreign consumption response. Finally, Eq. (13) states the trade balance response of relative factor prices to consumption discrepancies.

Having defined the elasticity of real expenditure, we are able to determine the stability conditions of the symmetric equilibrium. We assume that temporary adjustments follow a tâtonnement process where consumers adjust their choices and trade imbalances adjust the relative factor price. Symmetric stable equilibria are such that any small temporary shocks lead back to the symmetric configuration.

Lemma 1 The symmetric trade equilibrium with homogeneous populations is stable if and only if $\eta \geq 1$.

\section{Proof See "Appendix C".}

The trade equilibrium resumes to its interior value after a shock if and only if $\eta \geq 1$. This result is reminiscent of the Marshall-Lerner condition, establishing that a real devaluation (or depreciation) improves the trade balance only if the sum of countries' import-demand elasticities are higher than one (Caves et al. 2002). The result in Caves et al. (2002) applies for models with divisible goods whereas our model has unit purchase of many vertically differentiated heterogeneous goods. ${ }^{10}$

\footnotetext{
10 Equilibrium unstability also arises in exchange models with divisible goods depending on the shape of preferences and offer curves. For instance, in 2-agent and 2-divisible-good model, equilibria occur where
} 
As a result, countries with similar productivity and population share similar trade trade patterns. Otherwise, similar countries might end up with dissimilar trade patterns, a situation that lies out of the focus of this paper. In the sequel, we concentrate on stable equilibria by assuming $\eta>1$.

\subsection{Trade properties}

We now discuss the impact of population sizes and productivity on consumption and trade. Simplifying the above system of equations yields the following differences in the relative factor price and inverse marginal utility of domestic and foreign individuals:

$$
\begin{aligned}
\widetilde{w} & =-\frac{1}{\eta} \tilde{m}-\frac{1}{\eta} \widetilde{s} \\
\widetilde{\mu} & =-\frac{\eta+1}{2 \eta^{2}} \tilde{m}+\frac{\eta-1}{2 \eta^{2}} \widetilde{s}, \\
\tilde{\mu}^{*} & =-\frac{\eta-1}{2 \eta^{2}} \tilde{m}-\frac{\eta-1}{2 \eta^{2}} \widetilde{s} .
\end{aligned}
$$

The last two expressions allows us to infer the consumption of foreign high-quality goods $\left(\mathcal{H}^{*}(\mu)\right.$ and $\left.\mathcal{H}^{*}\left(\mu^{*}\right)\right)$. From (15), it comes

$$
\begin{aligned}
\tilde{\mu}-\widetilde{w} & =\frac{\eta-1}{2 \eta^{2}} \tilde{m}+\frac{3 \eta-1}{2 \eta^{2}} \widetilde{s}, \\
\tilde{\mu}^{*}-\widetilde{w} & =\frac{1+\eta}{2 \eta^{2}} \tilde{m}+\frac{1+\eta}{2 \eta^{2}} \widetilde{s},
\end{aligned}
$$

which determines the consumption of home high-quality goods $(\mathcal{H}(\mu / w)$ and $\left.\mathcal{H}\left(\mu^{*} / w\right)\right)$.

Note that the relative differences in $\tilde{\mu}$ and $\tilde{\mu}-\tilde{w}$ not only express the change in domestic consumer's real expenditures but also her incentives to purchase larger numbers of high quality imports and local products compared to the fully symmetric configuration. Those two variables indeed map to the differences in the number of purchased goods as it follows. Let $H(y)$ be the mass of high-quality goods $\mathcal{H}(y)$, which computes as $H(y)=\ell^{-1}(y)-\underline{z}$ with $\underline{z}=\inf \mathcal{Z}$. Then, any small relative difference $\tilde{y}=\mathrm{d} y / y$ induces a difference in the mass of high quality goods given by $\tilde{y} v(y)$ where $v(y)$ is the high-quality consumption elasticity

$$
\begin{aligned}
v(y) & \equiv \frac{\mathrm{d} \ln H(y)}{\mathrm{d} \ln y} \\
& =\frac{y}{H(y) \ell^{\prime}\left[\ell^{-1}(y)\right]}>0
\end{aligned}
$$

Footnote 10 continued agents' offer curves intersect and are stable according to whether the offer curves intersect from above or below. 
Table 3 Trade with homogeneous populations

\begin{tabular}{clll}
\hline & & $m \uparrow$ & $s \uparrow$ \\
\hline $\begin{array}{l}\text { Relative factor price } w \uparrow \\
\text { Consumption of high quality goods: } \\
\text { Domestic consumption }\end{array}$ & False & False \\
Foreign consumption & Local $\mathcal{H}(\mu / w) \uparrow$ & & True \\
& Import $\mathcal{H}^{*}(\mu) \uparrow$ & False & True \\
& Local $\mathcal{H}^{*}\left(\mu^{*}\right) \uparrow$ & False & False \\
\hline
\end{tabular}

$w$ is domestic factor price; $m$ is the relative size of home to foreign country; $s$ is home productivity; $\mathcal{H}$ is the set of high quality goods. The arrow $\uparrow$ reads as the set of home local high-quality goods expands. The table assumes stable equilibria $(\eta>1)$

Therefore, differences in population size $\widetilde{m}$ or productivity $\widetilde{s}$ lead to the following relative differences in the numbers of high-quality purchases: $\tilde{\mu} v\left(\mu^{0}\right)$ and $(\widetilde{\mu}-\widetilde{w}) v\left(\mu^{0}\right)$. For the sake of illustration, Table 2 reports the values for $v\left(\mu^{0}\right)$ in the four above examples. Since $v(y)>0$, the incentives to purchase high quality goods $\widetilde{\mu}$ and $(\tilde{\mu}-\widetilde{w})$ correspond to the consumption increases of those goods. ${ }^{11}$

Table 3 displays the main results of the paper on the impact of larger home population and productivity.

Table 3 allows us to discuss how population and productivity differences alter the baskets of high- and low-quality goods and foster countries' specializations. To be more precise, we say that those differences foster a country's specialization in high quality exports if they increase the share of high quality versus low quality goods in its exports. Similarly, they foster the specialization in high quality production if they increase the share of high quality versus low quality in its local production (for both local and foreign consumptions).

\subsubsection{Country size differences}

Consider a larger domestic population (second column). This inflates domestic labor supply (in terms of labor units) and therefore depresses the domestic wage and relative factor price (lower $w$, first row). The lower wage entices domestic individuals to purchase fewer high-quality imports $\left(\mathcal{H}^{*}(\mu)\right.$ shrinks, third row). The lower relative factor price makes domestic goods cheaper abroad and entices foreign consumers to import more numerous high-quality goods ( $H\left(\mu^{*} / w\right)$ expands, fifth row) ${ }^{12}$ The effect on the trade patterns is unambiguous: as the domestic population gets larger, the home country exports a larger number of high quality goods and imports a smaller number

11 In the example with isoelastic real expenditure, we have $\ell(z)=\left(\frac{1+z^{2}}{2}\right)^{1 / \alpha}$ and $\underline{z}=0$, so that the elasticity is equal to $v(y)=(\alpha-1) y^{\alpha+1} /\left(2 y^{\alpha}-1\right)$. In the example with linear real expenditure we have $\ell(z)=z^{2}$ and $\underline{z}=1$ so that $v(y)=\frac{1}{2} y^{1 / 2} /\left(y^{1 / 2}-1\right)>0$.

12 Note that domestic consumers switch from high quality to low quality products for imports but make the opposite switch for their local goods. This is because domestic goods become relatively cheaper with a lower relative price $w$. 
of them. To sum up, a larger domestic population fosters domestic specialization in the production of high quality goods and exports. By the same token, the foreign country specializes in lower quality production. It can be observed from (15) that a lower elasticity of real expenditure $\eta$ accentuates the impact of relative factor price and therefore increases such incentives to specialize.

Finally, whereas domestic consumers get a lower wage, they also face lower prices for local goods. Local high-quality goods are still attractive to them. Therefore, they substitute the high quality imports with local high-quality goods $(H(\mu / w)$ expands, second row). In any case, the home production of high quality goods is larger. Foreigners do exactly the opposite and substitute their local high-quality consumption with high-quality imports $\left(H^{*}\left(\mu^{*}\right)\right.$ shrinks, fourth row).

We summarize those results in the following proposition:

Proposition 1 A larger country population fosters its specialization in high quality exports and the other country specialization in low quality exports.

Several remarks can be made. First, it is easy to show that a larger population size has no effect on consumption in the closed economy version of this model. Because of the constant returns to production scale, additional individuals proportionally contribute to their own consumption of each type of goods. In the presence of trade, a rise in domestic population decreases the domestic costs of high and low quality goods in the same proportion so that the local production of those goods is given no relative advantages. However, it decreases the domestic cost per quality relative the other country, which entices specialization in higher quality goods. Second, the result about specialization parallels Fajgelbaum et al.'s (2011, Proposition 2(i)) finding that bigger countries become net exporters of high quality goods. Yet, whereas they explain this property through the existence of a 'home market effect', the current result is based on the relative price movements. Indeed in Fajgelbaum et al. (2011), there exists no relative wage effect stemming from the trade of differentiated goods because of the assumption of a perfectly tradeable homogeneous good.

\subsubsection{Productivity differences}

Consider the case of a large domestic productivity (third column in Table 3 ). This again inflates domestic labor supply (in terms of labor units) and depresses the domestic wage and the relative factor price (lower $w$, first row). However, although foreign goods become less attractive at home, the larger home productivity raises domestic workers' income. In the trade equilibrium, domestic consumers purchase more highquality goods from both local and foreign production $\left(\mathcal{H}(\mu / w)\right.$ and $\mathcal{H}^{*}(\mu)$ expand, second and third row). The higher domestic productivity benefits foreign consumers, too. Because of the terms of trade, their import prices are lower, which entices them to increase their expenditures on imported high-quality goods and drop some local highquality goods $\left(\mathcal{H}^{*}\left(\mu^{*}\right)\right.$ shrinks and $\mathcal{H}\left(\mu^{*} / w\right)$ expand, fourth and fifth columns). This comes at the expense of their consumption of low quality goods.

In sum, when countries are not too asymmetric, they export larger sets of high quality goods. They therefore jointly specialize in the production of those goods. 
Proposition 2 A larger domestic productivity fosters specialization in high quality export of both countries.

A rise in domestic productivity proportionally decreases the labor input needed of all domestic goods. It gives a domestic advantage in terms of per-quality input relative the other country and therefore entices home specialization in high quality goods. The point is that the rise in productivity also raises the purchasing power of domestic consumers who demand higher quality goods from abroad. As a result, the foreign country also specializes in high quality goods. This result is congruent to the empirical evidence that the quality of exports correlates with the productivity and income of the origin and destination countries (see the introduction).

\subsubsection{Linder hypothesis}

This model matches the empirical fact that two richer countries trade more high quality products. Indeed, extending the above analysis to equal increases in each country's productivity $\mathrm{d} s / s=\mathrm{d} s^{*} / s^{*}$, one can get that first $\widetilde{w}=0$. Relative factor prices are unaltered because of symmetry. Also, one gets that $\tilde{\mu}=\tilde{\mu}^{*}=\tilde{\mu}-\widetilde{w}=\tilde{\mu}^{*}-$ $\tilde{w}=\frac{1}{\eta} \widetilde{s}$. Therefore, when both countries become equally more productive, consumers purchase more numerous high-quality imports and local goods. Therefore, the two higher income countries specialize in the production of higher quality goods and trade more high-quality goods. Conversely, two low income countries will specialize in low quality goods and trade more of those. This confirms the Linder hypothesis about the nature of trade and the similarities of countries' demands.

Proposition 3 With homogeneous and symmetric populations, two higher income countries specialize in the production of higher quality goods and trade more of those.

Proof See "Appendix D".

This point has empirically been confirmed by Hummels and Klenow (2005) who show that more productive trade partners import goods of higher quality from the more productive exporters.

\subsection{Trade costs}

The recent trade literature emphasizes the role of trade costs. ${ }^{13}$ In this subsection, we investigate the effect of bilateral ad-valorem/iceberg trade costs. We show how trade costs can foster the substitution of high quality imports and the specialization in high quality goods.

Let us assume an iceberg trade cost be $\tau>1$ where the share $\tau-1$ of each imported good is lost between the trade origin and destination. The domestic price of an imported unit of foreign variety $z^{*}$ becomes $\tau p_{i}^{*}\left(z^{*}\right)=\tau w^{*} a_{i}\left(z^{*}\right), i=H, L$. A domestic consumer with inverse marginal utility $\mu$ purchases all high-quality imports

\footnotetext{
13 For instance Lai et al. (2020) investigate the impact on global welfare of a reduction in bilateral trade costs.
} 
with $z^{*}$ such that $\mu \geq \tau w^{*} \ell\left(z^{*}\right)$. Her set of imports of high-quality varieties is therefore given by

$$
\mathcal{H}^{*}\left(\frac{\mu}{\tau w^{*}}\right)=\left\{z^{*} \in \mathcal{Z}: \frac{\mu}{\tau w^{*}} \geq \ell\left(z^{*}\right)\right\}
$$

while her expenditure on those goods is given by $\int_{\mathcal{H}^{*}\left(\mu / \tau w^{*}\right)} \tau a_{H}(z) \mathrm{d} z+\int_{\mathcal{L}^{*}\left(\mu / \tau w^{*}\right)}$ $\tau a_{L}(z) \mathrm{d} z$, which is equal to $\tau E\left(\mu / \tau w^{*}\right)$ where $E$ is the real expenditure function defined in (5). The foreigners' set of high-quality imports and their related real expenditure function have the symmetric formulations $\mathcal{H}\left(\mu^{*} / \tau w\right)$ and $\tau E\left(\mu^{*} / \tau w\right)$. The local consumptions $\mathcal{H}(\mu / w)$ and $\mathcal{H}^{*}\left(\mu^{*} / w^{*}\right)$ and local real expenditures $E(\mu / w)$ and $E\left(\mu^{*} / w^{*}\right)$ are not affected by trade costs.

Using again the wage normalization $w^{*}=1$, the budget constraint and trade balance conditions write as

$$
\begin{gathered}
s=E\left(\frac{\mu}{w}\right)+\frac{\tau}{w} E\left(\frac{\mu}{\tau}\right), \\
s^{*}=E\left(\mu^{*}\right)+\tau w E\left(\frac{\mu^{*}}{\tau w}\right), \\
m \tau E\left(\frac{\mu}{\tau}\right)=\tau w E\left(\frac{\mu^{*}}{\tau w}\right) .
\end{gathered}
$$

When countries are fully symmetric $\left(s=s^{*}\right.$ and $\left.m=1\right)$, the equilibrium is the symmetric configuration where $w=1$ and $\mu=\mu^{*} \equiv \mu_{\tau}^{0}$ with $s=E\left(\mu_{\tau}^{0}\right)+$ $\tau E\left(\mu_{\tau}^{0} / \tau\right)$. Equilibrium conditions are similar to those presented in Table 2. As before, we assume that trade equilibrium stability conditions hold: $\eta\left(\mu_{\tau}^{0}\right)>1$ and $\eta_{\tau}=$ $\eta\left(\mu_{\tau}^{0} / \tau\right)>1$

One can differentiate the above system of equilibrium conditions around the symmetric configuration and solve for the small differences in wages and inverse marginal utility $\left(\tilde{w}, \tilde{\mu}, \tilde{\mu}^{*}\right)$ as functions of exogenous differences $(\tilde{m}, \tilde{s}, \tilde{\tau})$ where $\tilde{\tau}=\mathrm{d} \tau / \tau$. This yields the following expressions for the differences in relative price

$$
\widetilde{w}=-\frac{\xi}{\Phi} \tilde{m}-\frac{\eta_{\tau}}{\Phi} \tilde{s}
$$

and incentives to purchase high quality goods (see "Appendix D”)

$$
\begin{aligned}
\tilde{\mu}-\tilde{w} & =\frac{\phi_{\tau}\left(\eta_{\tau}-1\right)}{\Phi} \tilde{m}+\frac{\phi_{\tau} \eta_{\tau}^{2}+\left(2 \eta_{\tau}-1\right) \phi \eta}{\xi \Phi} \tilde{s}+\frac{\left(\eta_{\tau}-1\right) \phi_{\tau}}{\xi} \tilde{\tau} \\
\tilde{\mu}^{*} & =-\frac{\left(\eta_{\tau}-1\right) \phi_{\tau}}{\Phi} \tilde{m}-\frac{\eta_{\tau}\left(\eta_{\tau}-1\right) \phi_{\tau}}{\xi \Phi} \tilde{s}+\frac{\left(\eta_{\tau}-1\right) \phi_{\tau}}{\xi} \tilde{\tau} \\
\tilde{\mu}-\tilde{\tau} & =-\frac{(\eta-1) \phi+1}{\Phi} \tilde{m}+\frac{\eta\left(\eta_{\tau}-1\right) \phi}{\xi \Phi} \tilde{s}-\frac{\phi_{\tau}+\phi \eta}{\xi} \tilde{\tau} \\
\tilde{\mu}^{*}-\tilde{w}-\tilde{\tau} & =\frac{\phi_{\tau}+\phi \eta}{\Phi} \tilde{m}+\eta_{\tau} \frac{\left(\phi_{\tau}+\phi \eta\right)}{\xi \Phi} \tilde{s}-\frac{\phi_{\tau}+\phi \eta}{\xi} \widetilde{\tau}
\end{aligned}
$$


In those expressions $\eta=\eta\left(\mu_{\tau}^{0}\right)$ and $\eta_{\tau}=\eta\left(\mu_{\tau}^{0} / \tau\right)$ are the elasticity of real expenditure defined in (14) and evaluated at the inverse marginal utility in each local and import markets, $\phi=E\left(\mu_{\tau}^{0}\right) /\left[E\left(\mu_{\tau}^{0}\right)+\tau E\left(\mu_{\tau}^{0} / \tau\right)\right]$ and $\phi_{\tau}=1-\phi$ are the shares of real expenditures on local and imported goods, and finally $\Phi=\phi \eta\left(2 \eta_{\tau}-1\right)+\phi_{\tau} \eta_{\tau}$ and $\xi=\phi \eta+\phi_{\tau} \eta_{\tau}$ are positive bundles of terms.

It must first be noted that the signs of the coefficients on $\tilde{m}$ and $\tilde{s}$ in the above relationship are the same as in the model without trade costs. As a consequence, all the trade properties of stable equilibria with respect to population and productivity differences hold in the presence of trade cost. Furthermore, what is the effect of an increase in trade costs $(\tilde{\tau}>0=\tilde{m}=\widetilde{s})$ on the consumer's basket of goods? From the coefficients on $\tilde{\tau}$ in the above relationships, we infer that higher trade costs have no effect on relative prices $w$. This is because trade costs remain equal in both trade directions, so that higher trade costs equally shift the export and import values and do not change the trade balance between symmetric countries. They also expand the consumption sets of local high-quality goods $\mathcal{H}(\mu / w)$ and $\mathcal{H}^{*}\left(\mu^{*}\right)$ because $\tilde{\mu}-\widetilde{w}>0$ and $\tilde{\mu}^{*}>0$. By contrast, they reduce those of high quality imports $\mathcal{H}^{*}(\mu / \tau)$ and $\mathcal{H}\left(\mu^{*} / \tau w\right)$ because $\tilde{\mu}-\tilde{\tau}<0$ and $\tilde{\mu}^{*}-\widetilde{w}-\tilde{\tau}<0$. Trade costs therefore foster the substitution of high quality imports for high-quality local consumption, although not necessarily on a one-by-one basis.

Does trade integration increase countries' specialization in the production of high quality products? The changes in the number of high quality varieties produced at home are given by $(\tilde{\mu}-\tilde{w}) v(\mu / w)+\left(\tilde{\mu}^{*}-\widetilde{w}-\widetilde{\tau}\right) v\left(\mu^{*} / \tau w\right)$ where $v(y) \equiv \mathrm{d} \ln H(y) / \mathrm{d} \ln y>0$ is the high-quality consumption elasticity defined in (16). Plugging the above values of $\left(\tilde{\mu}, \widetilde{\mu}^{*}, \widetilde{w}\right)$ from (18) for $\widetilde{\tau}>0=\widetilde{s}=\tilde{m}$ and using symmetry, we infer that a fall in trade costs increases the home production of high quality goods if and only if $\phi_{\tau}\left(\eta_{\tau}-1\right) v\left(\mu_{\tau}^{0}\right)<\left(\phi_{\tau}+\phi \eta\right) v\left(\mu_{\tau}^{0} / \tau\right)$. The LHS reflects the positive effect of trade costs on home consumption while the RHS reflects the negative effect on exports. The net effect cannot be signed because we do not know how $\eta_{\tau}$ and $v\left(\mu_{\tau}^{0}\right)$ compare to $\eta$ and $v\left(\mu_{\tau}^{0} / \tau\right)$ for any $\tau$. Nevertheless, for small trade $\operatorname{costs}(\tau \rightarrow 1)$, this inequality holds as it simplifies to $2 \phi v\left(\mu_{\tau}^{0}\right)>0$. Hence, when trade costs are not too large, a reduction of trade barriers raises the number of high quality goods produced at home and therefore fosters specialization in the production of high quality goods. By symmetry this conclusion applies for the foreign country. We summarize the last results in the following proposition:

Proposition 4 Higher trade costs foster the substitution of high quality imports for high-quality local consumption. When trade costs are not too high, trade integration fosters the specialization in high quality goods in both countries.

The results in Proposition 4 are consistent with recent empirical findings on changes in trade costs (see Amiti and Khandelwal (2013), and Fan et al. 2015, among others).

\section{Heterogeneous populations}

It is well-known that trade has redistribution effects. However, the relationship between trade, product quality and the welfare of social groups has not been discussed in the 
trade literature. In this section, we investigate whether some income social groups may be harmed from high demography and productivity growth biased in favor of other groups. Toward this aim, we consider that populations are split into heterogeneous productivity groups. The presence of social groups differing in income implies that, at equilibrium, some income groups buy certain varieties at high quality and some at low quality. This is a relevant point of the paper, as it allows then to link our paper to the empirical analysis on trade, where unobserved quality is measured with the differences in prices among goods of the same variety.

Suppose that every population is divided in $K$ skill groups. For the sake of readability, we distinguish home and foreign groups by respectively using the group indices $k$ and $l \in\{1, \ldots, K\}$. Home individuals in group $k$ are endowed with $s_{k}$ labor units, which are distributed according to the group probability distribution $g_{k}\left(\sum_{k=1}^{K} g_{k}=1\right)$. The mass of this group is $M g_{k}$. For simplicity, we consider that domestic and foreign groups have symmetric distributions: $g_{l}^{*}=g_{k}$ for $l=k$. So, foreign individuals in groups $l$ are endowed with $s_{l}^{*}$ labor units and belong to a group of mass $M^{*} g_{l}$. We focus on countries that are not too asymmetric with respect to their productivity, population sizes and income distributions. We study the impact of small differences in such parameters.

At the equilibrium, the wage and the inverse marginal utility in group $k$ and $l$ are given by the scalars and vectors $\left(w,\left\{\mu_{k}\right\}_{k \in K},\left\{\mu_{l}^{*}\right\}_{l \in K}\right)$ that satisfy the expenditure identities and the balanced trade condition:

$$
\begin{aligned}
s_{k} & =E\left(\frac{\mu_{k}}{w}\right)+\frac{E\left(\mu_{k}\right)}{w}, \\
s_{l}^{*} & =E\left(\mu_{l}^{*}\right)+w E\left(\frac{\mu_{l}^{*}}{w}\right), \\
m \sum_{k=1}^{K} E\left(\mu_{k}\right) g_{k} & =w \sum_{l=1}^{K} E\left(\frac{\mu_{l}^{*}}{w}\right) g_{l}^{*} .
\end{aligned}
$$

Equilibrium conditions have the same structure as in the case of homogeneous population, except that the budget constraints (19) and (20) determine the inverse marginal utility in each consumer group and the trade balance condition (21) depends aggregates of the real expenditures in those groups.

We begin with the study of the equilibrium with symmetric populations and productivities: $m=1$ and $s_{k}=s_{l}^{*} \forall k=l$. At equilibrium, we obtain the symmetric configuration where $w=w^{0} \equiv 1$ and $\mu_{k}=\mu_{l}^{*} \equiv \mu_{k}^{0}$ for $k=l$ with $s_{k}=2 E\left(\mu_{k}^{0}\right)$. Because $E$ is an increasing function, the latter condition implies that richer consumers buy wider sets of high quality products. That is, $s_{k} \geq s_{k^{\prime}}$ implies that $\mu_{k} \geq \mu_{k^{\prime}}$ and $\mu_{k} / w \geq \mu_{k^{\prime}} / w$ so that $\mathcal{H}\left(\mu_{k}\right) \supseteq \mathcal{H}\left(\mu_{k^{\prime}}\right)$ and $\mathcal{H}\left(\mu_{k} / w\right) \supseteq \mathcal{H}\left(\mu_{k^{\prime}} / w\right)$. The symmetric trade equilibrium exists if it satisfies the restrictions on the image set of input-perquality $\ell$. Given that the functions $\ell$ and $E$ are independent of productivities $s_{k}$ and $s_{l}$, the restrictions are the same as those of the homogeneous population.

The consumption of high and low quality goods varies according to the country differences in each factor. We consider the small differences in domestic population $\tilde{m}=\mathrm{d} m / m>0$ and group $k$ 's domestic productivity $\tilde{s}_{k}=\mathrm{d} s_{k} / s_{k}>0$. Totally 
differentiating and simplifying the above system of equations around the symmetric equilibrium yields the following trade equilibrium conditions:

$$
\begin{aligned}
2 \tilde{s}_{k} & =2 \eta_{k} \tilde{\mu}_{k}-\left(\eta_{k}+1\right) \tilde{w}, \\
0 & =2 \eta_{l} \tilde{\mu}_{l}^{*}+\widetilde{w}\left(1-\eta_{l}\right), \\
\tilde{m}+\sum_{k} \varphi_{k} \eta_{k} \tilde{\mu}_{k} & =\widetilde{w}+\sum_{l} \varphi_{l} \eta_{l}\left(\tilde{\mu}_{l}^{*}-\widetilde{w}\right)
\end{aligned}
$$

where

$$
\eta_{k} \equiv\left[\frac{\mathrm{d} \ln E(y)}{\mathrm{d} \ln y}\right]_{y=\mu_{k}^{0}}>0 \text { and } \varphi_{k}=\frac{E\left(\mu_{k}^{0}\right) g_{k}}{\sum_{l} E\left(\mu_{l}^{0}\right) g_{l}}=\frac{s_{k} g_{k}}{\sum_{l} s_{l} g_{l}} \in[0,1],
$$

while summation operators apply on all groups $k, l \in\{1, \ldots, K\}$. There are two differences with the case of homogeneous population. On the one hand, the inverse marginal utility now depends on group-specific real expenditure elasticities $\eta_{k}$. On the other hand, the trade balance compares the averages of inverse marginal utility within domestic and foreign groups. Those averages are weighted by each group's share of labor supply, $\varphi_{k}$ (in labor units). Hence, groups with larger population and/or individual productivity have stronger impact on trade balance and therefore on the relative factor price $w$.

The symmetric trade equilibrium is subject to stability issues. Using the same tâtonnement process, we find that a stable trade equilibrium depends on the average elasticity of real expenditure as it follows:

Lemma 2 The symmetric trade equilibrium with heterogeneous populations is stable if and only if $\bar{\eta} \equiv \sum_{k=1}^{K} \varphi_{k} \eta_{k}>1$.

Proof See "Appendix E”.

This conditions is less restrictive than under homogeneous population as some group may have elasticity of real expenditure lower than one if some other group has it higher. Using the definition $\bar{\eta}=\sum_{j} \varphi_{j} \eta_{j}$, we can express the solution of the above equilibrium conditions as

$$
\begin{aligned}
\widetilde{w} & =-\frac{\tilde{m}}{\bar{\eta}}-\frac{1}{\bar{\eta}} \sum_{j} \varphi_{j} \tilde{s}_{j} \\
\tilde{\mu}_{k} & =-\frac{\eta_{k}+1}{2 \eta_{k} \bar{\eta}} \tilde{m}+\frac{1}{\eta_{k}} \widetilde{s}_{k}-\frac{\eta_{k}+1}{2 \eta_{k} \bar{\eta}} \sum_{j} \varphi_{j} \widetilde{s}_{j}, \\
\tilde{\mu}_{l}^{*} & =-\frac{\eta_{l}-1}{2 \eta_{l} \bar{\eta}} \tilde{m}-\frac{\eta_{l}-1}{2 \eta_{l} \bar{\eta}} \sum_{j} \varphi_{j} \tilde{s}_{j},
\end{aligned}
$$

where all sums are over groups $j \in\{1, \ldots, K\}$. The first expression gives the relative factor price. The two other expressions yield the consumptions of foreign high-quality goods. On the one hand, $\widetilde{\mu}_{k}$ gives the import set $\mathcal{H}^{*}\left(\mu_{k}\right)$ of the domestic group $k$ that 
Table 4 Trade with heterogeneous populations

\begin{tabular}{lllc}
\hline & & $m \uparrow$ & $s_{k} \uparrow$ \\
\hline $\begin{array}{l}\text { Relative factor price } w \uparrow \\
\text { Consumption of high quality goods: }\end{array}$ & & False & False \\
Domestic group $k$ & Local $\mathcal{H}\left(\mu_{k} / w\right) \uparrow$ & $\eta_{k}>1$ & True \\
& Import $\mathcal{H}^{*}\left(\mu_{k}\right) \uparrow$ & False & True \\
Domestic group $j \neq k$ & Local $\mathcal{H}\left(\mu_{j} / w\right) \uparrow$ & $\eta_{k}>1$ & $\eta_{j}>1$ \\
& Import $\mathcal{H}^{*}\left(\mu_{j}\right) \uparrow$ & False & False \\
Foreign consumption & Local $\mathcal{H}^{*}\left(\mu_{l}^{*}\right) \uparrow$ & $\eta_{l}<1$ & $\eta_{l}<1$ \\
& Import $\mathcal{H}\left(\mu_{l}^{*} / w\right) \uparrow$ & True & True \\
\hline
\end{tabular}

$w$ is domestic factor price; $m$ is the relative size of home to foreign country; $s_{k}$ is home group $k$ 's productivity; $\mathcal{H}$ is the set of high quality goods. The arrow $\uparrow$ reads as an expansion of the set of high-quality goods. The table assumes stable equilibria as expressed in Lemma 2

benefits from a productivity difference $\widetilde{s}_{k}$ above the respective foreign group's. On the other hand, $\tilde{\mu}_{l}^{*}$ gives the foreign consumption of own high-quality goods $\mathcal{H}^{*}\left(\tilde{\mu}_{l}^{*}\right)$. From this, we also derive the incentives to consume domestic high-quality goods by home and foreign consumers as

$$
\begin{aligned}
& \tilde{\mu}_{k}-\tilde{w}=\frac{\eta_{k}-1}{2 \eta_{k} \bar{\eta}} \tilde{m}+\frac{1}{\eta_{k}} \widetilde{s}_{k}+\frac{\eta_{k}-1}{2 \eta_{k} \bar{\eta}} \sum_{j} \varphi_{j} \tilde{s}_{j}, \\
& \tilde{\mu}_{l}^{*}-\tilde{w}=\frac{\eta_{l}+1}{2 \eta_{l} \bar{\eta}} \tilde{m}+\frac{\eta_{l}+1}{2 \eta_{l} \bar{\eta}} \sum_{j} \varphi_{j} \tilde{s}_{j} .
\end{aligned}
$$

For $K=1$, those expressions collapse to the ones obtained under homogeneous populations.

Table 4 displays the effect of a larger home population $(\tilde{m}>0)$ and of a larger productivity in group $k$, other groups $j$ keeping same productivity across countries $\left(\tilde{s}_{k}>0=\tilde{s}_{j}, j \neq k\right)$. Results readily obtain from the previous expressions. Results simplify thanks to stability condition in Lemma 2 (see "Appendix F").

For the sake of clarity, we keep consistency with the section with homogeneous population and focus on the case where real expenditure elasticities $\eta_{k}$ are larger than one for all groups. In this case, one checks that all the inequalities presented in Table 4 have same direction as in Table 3. Demographic and productivity differences therefore yield effects on high- and low-quality good consumptions that are qualitatively similar to those reported in Table 3. The impact of changes in population size is similar to that in the case with homogeneous populations, and can readily be inferred from the second column of Table 4 . When the home population is larger, every domestic skill group consumes a wider range of local high-quality goods and a smaller range of high-quality imports than it would do in absence of any population difference. By contrast, the foreign population consumes a lower number of local high-quality goods and a larger number of high-quality imports. This fosters domestic specialization in the production of high quality goods and exports. The opposite occurs abroad. Hence, the direction of the effects of population differences are unaltered by countries' income 
heterogeneity. Yet, amplitudes differ because of the idiosyncratic behaviors of income groups, captured in the $\eta_{k}$ 's.

We now investigate the impact of productivity differences within home and foreign groups.

Proposition 5 Consider two countries with identical skill groups with $\eta_{k} \geq 1$ except that the domestic skill group $k$ gets a larger productivity compared to its counterpart foreign group $l=k$. This fosters home's specialization in high quality exports and raises total export values. It benefits this group and other foreign groups but harms other domestic skill groups. Finally, it fosters foreign specialization in high quality exports only if group $k$ is large enough.

\section{Proof See "Appendix G”.}

The argument for this proposition can partly be obtained from the third column of Table 4 . When the home population includes a skill group $k$ with productivity higher than its corresponding foreign skill group, this augments the domestic effective labor supply and reduces the relative prices. Because it increases its income, this domestic group purchases a wider range of both local and foreign high-quality goods than it would do in absence of such difference (see row 2 and 3).

A domestic skill group $j$ that does not benefit from a productivity advantage gets a lower income and an adverse term of trade effect. It then chooses to purchase a wider range of local high-quality goods and a narrower range of high-quality imports (row 4 and 5). In the end, it can be shown that it overall consumes a lower number of high quality goods (see "Appendix G"). By contrast, foreign groups face a favorable term of trade so that they purchase a wider range of high-quality imports and restrain the range of their local high-quality consumption (row 6 and 7).

The group $k$ 's larger productivity indeed leads to a larger number of high-quality exports to the foreign country, which implies domestic specialization in high-quality exports. However, in contrast to the case with homogeneous population, it is not $a$ priori clear whether the foreign country follows the same specialization process. This is because, under heterogeneous population, the domestic group $k$ purchases a higher number of high-quality imports but other domestic groups do the opposite. The effect on the volume of domestic high-quality import then depends on the groups' shares in the domestic population. In particular, if the group $k$ has a small share in the domestic population, it is unlikely to boost foreign high-quality exports.

Proposition 5 is meant to be applied in the context of skill bias technological changes, which receives much attention in the literature. Classical evidence for the United States is provided by Berman et al. (1994), Goldin and Katz (1998) and Autor et al. (2003), among others, where it emerges a link between job polarization and rapid improvements in the productivity of information and communications technologies. ${ }^{14}$ In particular, one may consider that recent technological changes have favored U.S. high skilled workers. Our model then implies that such changes foster U.S. specialization in high quality exports, enhance U.S. trade values and benefit U.S. high skilled

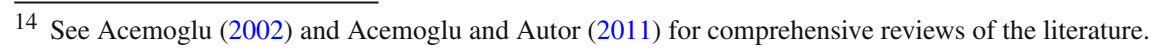


workers at the expense of U.S. low skill workers. Those technological changes may lead to fewer high-quality imports if U.S. high skill group is not large enough. ${ }^{15}$

This idea is confirmed by the findings that relate skills to trade outcomes. In his analysis of North-South trade, Wood (1995) argues that unskilled workers in the South country benefits most from trade, whereas in the North, unskilled workers are worse off, while skilled workers gain from trade. Similarly, Acemoglu (2003) provides a theoretical framework where international trade and skill-biased technical change explain wage inequality. More recently, using a calibrated open economy Ramsey model, Ratts $\varnothing$ and Stokke (2013) find that trade effects via technology adoption and skill bias can be an important determinant of wage inequality. Proposition 5 is consistent with this view if one considers the increase in the high skilled group's productivity in Northen countries. Finally, Verhoogen (2008) relates quality upgrading to inequality albeit, in this paper, inequality is determined at intra-industry trade level by exchange rate devaluation.

\section{Discussions}

The present model for vertical differentiation and trade faces several limitations. Namely, it is studied under the assumptions of full market coverage, closely symmetric country productivity and population, symmetric technologies, fixed number of goods and absence of comparative advantages. As in the industrial organization literature, the first assumption is difficult to relax without analytical complications. The second assumption is relaxed in a companion paper (Picard and Tampieri 2019). We here explain how the three other limitations can be dealt with. ${ }^{16}$

Asymmetric technologies In the above analysis, countries have symmetric production functions. The assumption of symmetric technologies can readily be relaxed in the following way so that it entails the same effect as country productivity differences. Suppose indeed an asymmetric technological structure of the two countries such that the foreign labor input is given by $a_{i}^{*}(z)=a_{i}(z) / \delta, i \in\{H, L\}$ where $\delta>0$ is the foreign technology parameter. This implies that the foreign perquality input profile simplifies to $\ell^{*}(z)=\ell(z) / \delta$. The set of foreign high-quality goods consumed at home is then given by $\mathcal{H}\left(\delta \mu / w^{*}\right)$. The domestic expenditure on imports is given by $\int_{\mathcal{H}\left(\delta \mu / w^{*}\right)} w^{*} a_{H}(z) / \delta \mathrm{d} z+\int_{\mathcal{L}\left(\delta \mu / w^{*}\right)} w^{*} a_{L}(z) / \delta \mathrm{d} z$ and reduces to $\left(w^{*} / \delta\right) E\left(\delta \mu / w^{*}\right)$. The same argument applies for the goods consumed by foreign consumers. Hence, making the normalization $w^{*} / \delta=1$, we get exactly the same system of trade conditions as (4)-(5), except that $s^{*}$ here becomes $s^{*} \delta$. As a result, an increase in foreign technology parameter $\delta$ has the same effect as an increase in the foreigners' individual productivity $s^{*}$.

\footnotetext{
15 Similar findings for the U.S. as well as other developed countries can be found in Berman et al. (1998), Machin and Van Reenen (1998) and Cho and Díaz (2019).

16 We thank a referee for suggesting this discussion.
} 
Asymmetric number of varieties The assumption of the symmetric number of goods in both countries can also be relaxed in the following way. In the spirit of Melitz (2003), let us redefine the set of domestic and foreign product varieties as $\mathcal{Z} \times[0, n]$ and $\mathcal{Z} \times\left[0, n^{*}\right]$ where $n>0$ and $n^{*}>0$. Accordingly, the number of domestic and foreign goods are equal to $Z n$ and $Z n^{*} .{ }^{17}$ The utility writes as $U=n \int_{\mathcal{Z}}\left(\sum_{i=H, L} b_{i}(z) x_{i}(z)\right) \mathrm{d} z+n^{*} \int_{\mathcal{Z}}\left(\sum_{i=H, L} b_{i}\left(z^{*}\right) x_{i}^{*}\left(z^{*}\right)\right) \mathrm{d} z^{*}$ while the real expenditure for home goods and imports are given by $n E(y)$ and $n^{*} E(y)$ where $y \in\left\{\mu, \mu / w, \mu^{*}, \mu^{*} / w\right\}$. The set of high-quality local consumption expands to $\mathcal{H}(\mu / w) \times[0, n]$ where $\mathcal{H}(\mu / w) \equiv\{z \in \mathcal{Z}: \mu / w \geq \ell(z)\}$ and $\ell(z)$ are defined as before. The equilibrium conditions become

$$
\begin{aligned}
s & =n E\left(\frac{\mu}{w}\right)+\frac{1}{w} n^{*} E(\mu), \\
s^{*} & =n^{*} E\left(\mu^{*}\right)+w n E\left(\frac{\mu^{*}}{w}\right), \\
m n^{*} E(\mu) & =w n E\left(\frac{\mu^{*}}{w}\right) .
\end{aligned}
$$

The effect of the number of domestic firms $n$ can be easily studied by totally differentiating around the symmetric configuration as in the above text $\left(n=n^{*}\right.$ while $\tilde{n}=d n / n$ and $d n^{*} / n^{*}=0$ ). It can be shown that a larger number of domestic firms brings about an increase in the domestic relative price. This is intuitive since all goods are consumed and the same domestic labor force is asked to produce more goods. The larger number of domestic goods raises the relative income at home and diminishes it abroad, and also implies that the budget for each good decreases. Hence foreigners gain from product diversity but react by spreading their income on lower quality goods.

Yet, for the sake of more realism, it is advisable to incorporate in this extension a system of economic forces that determine the product diversity. Such mechanisms can for instance be borrowed from the literatures on innovation or agglomeration economies. A thorough study lies out to the scope of the current paper.

Comparative advantages Many trade theory papers discuss the role of countries' technological advantages. For instance, Matsuyama (2000) discusses an asymmetric setting where the North country has an absolute advantage. In this subsection, we present a situation where productivity advantages are balanced and show how our model can be extended to comparative advantages in a North-North trade setting.

Towards this aim, it is possible to present a setup with comparative advantages that disentangles the production and consumption decisions. For instance, assume now that the varieties $z$ can be produced at different costs $a_{i}(z)$ at home and $a_{i}^{*}(z)$ abroad while the varieties $z^{*}$ are produced respectively at $a_{i}\left(z^{*}\right)$ and $a_{i}^{*}\left(z^{*}\right), i=$ $H, L$. Further assume the following chain of comparative advantages (Dornbusch et al. 1977): $\gamma(z)=a_{H}^{*}(z) / a_{H}(z)=a_{L}^{*}(z) / a_{L}(z)$ and $1 / \gamma\left(z^{*}\right)=a_{H}^{*}\left(z^{*}\right) / a_{H}\left(z^{*}\right)=$ $a_{L}^{*}\left(z^{*}\right) / a_{L}\left(z^{*}\right)$ where $\gamma^{\prime}>0, z \in \mathcal{Z}$ and $z^{*} \in \mathcal{Z}$. This says that varieties with

\footnotetext{
17 The important difference with Melitz (2003) is that $n$ is exogenously given in the present extension.
} 
high indices $z$ and $z^{*}$ are less costly to produce respectively at home and abroad. The production location of the same high- and low-quality variety will occur in the same country. This is because a firm will produce variety $z$ at home if $a_{i}(z) w \leq a_{i}^{*}(z) w^{*}$ and abroad otherwise, for $i=L, H$. That is, the same condition $\gamma(z) \geq w / w^{*}$ applies at any quality level $i=L, H$. By the same argument, a variety $z^{*}$ will be produced at home if $1 / \gamma\left(z^{*}\right) \geq w / w^{*}$. Hence, the good $z$ and $z^{*}$ is produced at home if $z<$ $\widehat{z} \equiv \gamma^{-1}\left(w / w^{*}\right)$ and $z^{*}>\widehat{z}^{*} \equiv \gamma^{-1}\left(w^{*} / w\right)$. Therefore, the comparative advantage is related to the specialization in terms of variety but not quality. In other words, if there exists a cost advantage to produce Feta-style cheese in Germany compared to Greece, this advantage equally applies for the high and low quality Feta cheeses. In the symmetric equilibrium configuration, we get $\widehat{z}=\widehat{z}^{*}=\gamma^{-1}(1)$. The study of closely asymmetric countries then sum up to the study of small changes in those variables. By defining the expenditure functions with these consumption sets, it is possible to close the model in a similar way as the baseline. ${ }^{18}$

\section{Concluding remarks}

This paper discusses a trade model with vertical differentiation embodied a set of horizontally differentiated goods. Individuals have non-homothetic preferences and purchase a unit of each differentiated good versioned in two qualities. In contrast the previous literature studying asymmetric production capabilities of product quality in North-South trade, this paper focuses on countries with similar production capabilities. We consider countries that slightly differ in their population and productivity. We show that a larger population leads to the specialization in high-quality production and highquality exports and to the specialization of the trading partner into low quality exports. By contrast, a larger domestic productivity fosters specialization in high quality export of both countries. Those results stem the effect of relative factor prices (terms of trade). It furthermore confirms Linder's (1961) prediction that two richer countries consume, produce and trade more high quality goods. Trade costs do not alter those results for closely symmetric countries. Yet, we show that smaller trade costs spur specialization in high quality exports.

The model also allows to discuss the relationship between trade, product quality and the welfare of various income groups. We divide each country's workers in symmetric skill groups. We confirm that larger domestic population fosters specialization in the production of high quality goods and exports of both countries. If a skill group gets a higher productivity, it is enticed to purchase more numerous high-quality imports and local goods. It benefits this group and other foreign groups but harms other domestic skill groups. Such skill group's productivity difference fosters home's specialization in high quality exports and raises total export values. The model offers a likely explanation about recent technological changes that have favored U.S. high skilled workers. In this model, such changes indeed foster specialization in high quality exports, enhance trade values and benefit high skilled workers at the expense of low skill ones. Our analysis is

\footnotetext{
18 A thorough analysis of comparative advantages and vertical differentiation is presented in Picard and Tampieri (2016).
} 
the first to show how such changes can be related to the production and consumption of vertically differentiated goods.

Our results hinge on non-homotheticity of preferences where richer and poorer workers have different marginal utility of consumption. In contrast to the literature, the paper presents trade properties for similar countries and for a wide class of primitives defining vertical differentiation. As in Matsuyama (2000), most properties must be determined about symmetric trade configurations. Nevertheless, we have presented examples to illustrate the relevance and properties of the model. Those examples might be expanded to study trade with multiple countries, multiple income groups, extensive margins, monopolistic competition, etc. This is left for future research.

Acknowledgements Open access funding provided by Università degli Studi di Firenze within the CRUICARE Agreement.

Open Access This article is licensed under a Creative Commons Attribution 4.0 International License, which permits use, sharing, adaptation, distribution and reproduction in any medium or format, as long as you give appropriate credit to the original author(s) and the source, provide a link to the Creative Commons licence, and indicate if changes were made. The images or other third party material in this article are included in the article's Creative Commons licence, unless indicated otherwise in a credit line to the material. If material is not included in the article's Creative Commons licence and your intended use is not permitted by statutory regulation or exceeds the permitted use, you will need to obtain permission directly from the copyright holder. To view a copy of this licence, visit http://creativecommons.org/licenses/by/4.0/.

\section{Appendix A: Examples of primitives}

We here compute the elements of Table 1.

Example (isoelastic real expenditure a) Consider the primitives $\mathcal{Z}=[0,1], a_{L}(z)=z$, $a_{H}(z)=2 z, b_{H}(z)=(\beta+1) z\left(\frac{1+z^{2}}{2}\right)^{-1 / \alpha}, b_{L}(z)=\beta z\left(\frac{1+z^{2}}{2}\right)^{-1 / \alpha}$ where $\alpha>1$ and $\beta>1$. Under such primitives, the cost and utility increments of low and high quality versions are kept in constant proportions. The cost of a product linearly increases with its "address" $z$ while the utility increment from its use increases at a smaller pace with it. In other words, more costly products bring lower utility increments. Then, per-quality input is given by $\ell(z)=\left(\frac{1+z^{2}}{2}\right)^{1 / \alpha}$ and the real expenditure function by $E(y)=y^{\alpha}$. One can check that the image set of $\ell$ lies above the schedule $a_{H} / b_{H}$ and that $a_{L} / b_{L} \leq \mu / w$ if $\mu / w \geq 1 / \beta$. Note that the elasticity of real expenditure $\mathrm{d} \ln E / \mathrm{d} \ln y$ is equal to the constant $\alpha$ and larger than one. Finally, a domestic individual buys $\ell^{-1}(\mu / w)$ and $\ell^{-1}(\mu)$ high quality from home and abroad and get a utility $V(\mu)+V(\mu / w)$ where one computes $\ell^{-1}(y)=\left(2 y^{\alpha}-1\right)^{1 / 2}$ and $V(y) \equiv \int_{0}^{\ell^{-1}(y)} b_{H}(z) \mathrm{d} z+\int_{\ell^{-1}(y)}^{1} b_{L}(z) \mathrm{d} z=\frac{\alpha \beta}{\alpha-1} y^{\alpha-1}+\frac{\alpha \beta}{\alpha-1}\left(1-2^{1 / \alpha}\right)$.

Example (linear real expenditure, a) Consider the primitives $\mathcal{Z}=\left[1, \kappa^{1 / 2}\right], a_{L}(z)=$ $2 z, a_{H}(z)=4 z, b_{L}(z)=2 \gamma / z$ and $b_{H}(z)=2(1+\gamma) / z$ where $\kappa>1$ and $\gamma>1$. As in the previous example, the cost and utility increments of low and high quality versions are kept in constant proportions while more costly products bring lower utility increments. Then, per-quality input is given by $\ell(z)=z^{2}$ and the real expenditure function by $E(y)=y+\kappa-2$. One can check that the image set of $\ell$ lies above 
the schedule $a_{H} / b_{H}$ and that $a_{L} / b_{L} \leq \mu / w$ if $\mu / w \geq \kappa /(1+\gamma)$. The elasticity $\mathrm{d} \ln E / \mathrm{d} \ln y$ is larger than one if and only if $\kappa \leq 2$. It also increases with higher $y$. Also, we compute the mass of high quality purchases $\ell^{-1}(y)=y^{1 / 2}$ and associated utility level $V(y) \equiv \int_{1}^{\ell^{-1}(y)} b_{H}(z) \mathrm{d} z+\int_{\ell^{-1}(y)}^{\kappa^{1 / 2}} b_{L}(z) \mathrm{d} z=\ln y+\gamma \ln \kappa^{1 / 2}$.

Example (isoelastic real expenditure $b$ ) Consider the primitives $\mathcal{Z}=[0,1), a_{L}(z)=$ $1, a_{H}(z)=1+\alpha(1-z)^{-\alpha-1}, b_{L}(z)=1$ and $b_{H}(z)=1+\alpha(1-z)^{-\alpha}$ with $\alpha>1$. Here, low quality versions yield the same cost and utility increments to users. The cost of high quality goods rises above the cost of low quality goods with the product "address" $z$ and tend to infinity for $z \rightarrow \bar{z}$. The utility increment of high quality goods also rises with $z$ but at a slower pace, which makes unattractive high quality version of goods with addresses $z \rightarrow \bar{z}$. Then, $\ell(z)=(1-z)^{-1}$ has image on $[1, \infty)$ and $\ell^{-1}(y)=1-y^{-1}$. The real expenditure is given by $E(y)=\int_{0}^{\ell^{-1}(y)} \alpha(1-z)^{-\alpha-1} \mathrm{~d} z+1=y^{\alpha}$. It can be checked that $a_{H} / b_{H} \leq \ell$ and $a_{L} / b_{L} \leq \mu / w$ if $\mu / w \geq 1$. Finally, we compute the associated utility level $V(y)=\int_{0}^{l^{-1}(y)} b_{H} d z+\int_{0}^{1} b_{L} d z=\left(\frac{\alpha}{\alpha-1} y^{\alpha}-1\right) / y+(2-\alpha /(\alpha-1))$, which is an increasing function of $y$.

Example (linear real expenditure, $b$ ) Consider the primitives $\mathcal{Z}=[\underline{z}, \bar{z}), \underline{z} \geq 0, \bar{z} \geq 1$, $a_{L}(z)=1, a_{H}(z)=1+\bar{z}^{2} /(\bar{z}-z)^{2}, b_{L}(z)=1$ and $b_{H}(z)=1+1 /(\bar{z}-z)$. Low quality versions yield the same cost and utility increment to users. The cost of high quality goods rises above the cost of low quality goods with the product "address" $z$ and tend to infinity for $z \rightarrow \bar{z}$. The utility increment of high quality goods also rises with $z$ but at a slower pace, which makes unattractive high quality version of goods with addresses $z \rightarrow \bar{z}$. per-quality input is given by $\ell(z)=\bar{z}^{2} /(\bar{z}-z)$, which maps to the image set $\left[\bar{z}^{2} /(\bar{z}-\underline{z}), \infty\right)$. One can check that the image set of $\ell$ lies above the schedules $a_{H} / b_{H}$ and that $a_{L} / b_{L} \leq \mu / w$ if $\mu / w \geq 1$. The real expenditure function is given by $E(y)=y-\varsigma$ where $\varsigma=z(2 \bar{z}-z) /(\bar{z}-z)>0$. It is positive for $y \geq \varsigma$. Its elasticity $\mathrm{d} \ln E / \mathrm{d} \ln y=y /(y-\bar{\zeta})$ is larger than one for $y \geq \varsigma$. The mass of high quality purchases is computed as $\ell^{-1}(y)=\bar{z}^{2}(1 / \bar{z}-1 / y)$ and its respective utility level as $V(y) \equiv \int_{\underline{z}}^{\ell^{-1}(y)} b_{H}(z) \mathrm{d} z+\int_{\ell^{-1}(y)}^{\bar{z}} b_{L}(z) \mathrm{d} z=\ln y+\left(\bar{z}-\underline{z}-\ln \frac{\bar{z}^{2}}{\bar{z}-\underline{z}}\right)$.

\section{Appendix B: Equilibrium conditions}

We here compute the equilibrium conditions in Table 2.

Example (isoelastic real expenditure a, continued) In this case, recall that $E(y)=$ $y^{\alpha}$ and $\ell(z)=\left(\frac{1+z^{2}}{2}\right)^{1 / \alpha}$. Then, the symmetric trade equilibrium is given by $s=$ $2 E\left(\mu^{0}\right)=2\left(\mu^{0}\right)^{\alpha}$, or equivalently, $\mu^{0}=(s / 2)^{1 / \alpha}$. The trade equilibrium exists if the first restriction $s \in[1,2]$ and the second restriction $\mu^{0} \geq 1 / \beta$ hold. This implies that $s \in[1,2]$ and $\beta^{\alpha} \geq 2$.

Example (linear real expenditure a, continued) We here obtained $\ell(z)=z^{2}$ and $E(y)=y+(\kappa-2)$. Then, the symmetric trade equilibrium is given by $s=2 E\left(\mu^{0}\right)=$ $2\left(\mu^{0}+\kappa-2\right)$, so that $\mu^{0}=s / 2+2-\kappa$. The first restriction imposes $s \in[2 \kappa-2,4 \kappa-4]$. 
The second restriction is is satisfied if $\mu^{0} \geq \kappa /(1+\gamma)$. That is, if $\kappa \leq 1+\gamma$ and $s \in[2 \kappa-2,4 \kappa-4]$.

Example (isoelastic real expenditure $b$, continued) We obtained $\ell(z)=(1-z)^{-1}$ and $E(y)=y^{\alpha}$. The symmetric trade equilibrium is given by $s=2 E\left(\mu^{0}\right)=2\left(\mu^{0}\right)^{\alpha}$, so that $\mu^{0}=(s / 2)^{1 / \alpha}$. It has been checked that $a_{H} / b_{H} \leq \ell$ and $a_{L} / b_{L} \leq \mu / w$ if $\mu / w \geq 1$. The last condition applied at $\mu^{0}$ implies $s \geq 2$.

Example (linear real expenditure $b$, continued) For this case, we computed $\ell(z)=$ $\bar{z}^{2} /(\bar{z}-z)$ and $E(y)=y-\varsigma$. Then, the symmetric trade equilibrium is given by $s=2 E\left(\mu^{0}\right)=2\left(\mu^{0}-\varsigma\right)$, so that $\mu^{0}=s / 2+\varsigma$. Note that the image set of $\ell$, i.e. $\left[\bar{z}^{2} /(\bar{z}-\underline{z}), \infty\right)$, always includes $\mu^{0}$ as $\mu^{0}>\bar{z}^{2} /(\bar{z}-\underline{z}) \Longleftrightarrow s \geq 2(\bar{z}-\underline{z})$. In contrast with the previous example, those primitives impose no productivity upper bound. It has been shown before that the image set of $\ell$ lies above the schedules $a_{H} / b_{H}$ while $\mu^{0} \geq a_{L} / b_{L}$ if $s / 2+\varsigma \geq 1$. Reshuffling the last condition we get the sufficient conditions $\bar{z}^{2}>(\bar{z}-\underline{z})$ and $s \geq 2(\bar{z}-\underline{z})$.

We here compute the stability conditions in Table 2.

Example (isoelastic real expenditure, continued) The primitives in this example have implied the constant elasticity of real expenditure $\eta=\alpha>1$ and leads to a stable symmetric trade equilibrium.

Example (linear real expenditure a, continued) The elasticity of real expenditure was computed as $\eta=[\mathrm{d} \ln E(y) / \mathrm{d} \ln y]_{y=\mu^{0}}=\mu^{0} /\left(\mu^{0}+(\kappa-2)\right)$, which is larger than one if $\kappa \leq 2$. Under this condition, the symmetric equilibrium is stable. For $\kappa>2$, it is unstable.

Example (linear real expenditure b, continued) The elasticity of real expenditure has been given by $\eta=[\mathrm{d} \ln E(y) / \mathrm{d} \ln y]_{y=\mu^{0}}=(s+2 \varsigma) / s$. This is larger than one if $\varsigma \geq 0$. Since this is true, the symmetric equilibrium is always stable.

\section{Appendix C: Stability conditions}

We here study the stability of the trade equilibrium in the case of homogeneous populations.

Definition of stable trade equilibria In this subsection we introduce the time dimension $t$ and follow Amano's (1968) stability analysis, which formalizes Marshall's (1879) approach. We consider the tâtonnement process where consumers adjust their choices and trade imbalances adjust the relative factor price (exchange rate) according to the following motion equation system:

$$
\begin{aligned}
\frac{\mathrm{d} \tilde{\mu}}{\mathrm{d} t} & =-\frac{\theta_{1}}{2 \eta}[2 \eta \tilde{\mu}-(1+\eta) \widetilde{w}], \\
\frac{\mathrm{d} \tilde{\mu}^{*}}{\mathrm{~d} t} & =-\frac{\theta_{1}}{2 \eta}\left[2 \eta \tilde{\mu}^{*}-(\eta-1) \tilde{w}\right], \\
\frac{\mathrm{d} \tilde{w}}{\mathrm{~d} t} & =-\theta_{2}\left[\tilde{w}+\eta\left(\tilde{\mu}-\tilde{\mu}^{*}\right) /(\eta-1)\right],
\end{aligned}
$$


Table 5 Four model examples: stability conditions

\begin{tabular}{llllll}
\hline & \multicolumn{2}{l}{ Linear expenditure } & & \multicolumn{2}{l}{ Isoelastic expenditure } \\
\cline { 2 - 3 } & (a) & (b) & (a) & (b) \\
\hline Stability condition $(\eta>1)$ & $\kappa \in[1,2]$ & Always holds & & Always holds & Always holds
\end{tabular}

where $\theta_{1}$ and $\theta_{2} \in(0,1)$ are adjustment speed parameters with $\theta_{1}+\theta_{2}=1$ without loss of generality. Accordingly, domestic consumers decrease their consumption if they spend more than their income. The trade balance adjusts to a lower relative price (exchange rate) when domestic consumers import too much. We define that a trade equilibrium $\left(\tilde{\mu}^{0}, \tilde{\mu}^{* 0}, w^{0}\right)$ is stable if any small deviations from it lead back to it.

Proof of Lemma 1 The trade equilibrium is stable if, after slight perturbation to $\left.\left(\tilde{\mu}_{1}, \tilde{\mu}_{1}^{*}, \widetilde{w}_{1}\right)\right)$, it converges back to its initial value $\left(\tilde{\mu}^{0}, \widetilde{\mu}^{* 0}, \widetilde{w}^{0}\right)$. The solution of this linear system of ordinary differential equations is given by $\left(\tilde{\mu}, \tilde{\mu}^{*}, \widetilde{w}\right)=$ $\left(\tilde{\mu}_{1}, \tilde{\mu}_{1}^{*}, \widetilde{w}_{1}\right) e^{y t}$ where $y$ is an eigenvalue of the above motion equation system. The equilibrium is stable if all eigenvalues $y$ have negative real parts. The eigenvalues solves the characteristic polynomial, which computes as $P(y)=$ $\left(y+\theta_{1}\right)\left[(\eta-1) y^{2}+y(\eta-1)+\eta \theta_{1} \theta_{2}\right]$. If $\eta=1$, this gives $y=-\theta_{1}<0$ so that the equilibrium is stable. If $\eta \neq 1$, this adds the two eigenvalues $y=-\frac{1}{2} \pm \frac{1}{2} \sqrt{\rho}$ where $\rho=\frac{\eta\left(\theta_{1}-\theta_{2}\right)^{2}-1}{\eta-1}$. Note that $0<\left(\theta_{1}-\theta_{2}\right)^{2}<1$. Then, if $\eta>1, \rho=$ $\frac{\eta\left(\theta_{1}-\theta_{2}\right)^{2}-1}{(\eta-1)} \in\left(-\frac{1}{\eta-1}, 1\right)$. For $\left(-\frac{1}{\eta-1}, 0\right), y$ is complex but $\operatorname{Re} y=-\frac{1}{2}<0$. For $\rho \in(0,1), y$ is real and always negative. So, $y$ has negative real part for $\eta>1$. If $\eta<1, \rho=\frac{\eta\left(\theta_{1}-\theta_{2}\right)^{2}-1}{(\eta-1)} \in\left(1, \frac{1}{1-\eta}\right)$ so that the largest root $y=-\frac{1}{2}+\frac{1}{2} \sqrt{\rho}>0$. So, $y$ is positive for $\eta<1$. To sum up, the trade equilibrium is stable if $\eta>1$.

Examples Table 5 gives the stability conditions for our illustrative examples. The stability condition is not very restrictive. There is indeed no restriction in 3 out of 4 examples. In the only restrictive example (linear exp. (a)), the part of the restriction comes from the assumptions of "full market coverage".

Factors affecting stability Since stability depends on the elasticity $\eta$, it is worth explaining the factors that affects it. For this purpose, it is helpful to derive the value of elasticity.

Corollary 1 Income is negatively related to the elasticity of the inverse marginal utility, i.e.,

$$
\eta=\frac{1}{\frac{\mathrm{d} \ln \mu^{0}(s)}{\mathrm{d} \ln s}}=\frac{2}{s}\left[\frac{z\left(a_{H}-a_{L}\right)}{\frac{d \ln \ell}{d \ln z}}\right]_{z=z^{0}},
$$

where $z^{0}$ is the index of the good that makes individuals indifferent to any quality version (i.e. solution of $\ell\left(z^{0}\right)=\mu^{0}$ ). 
Proof The formula of elasticity is

$$
\eta \equiv\left[\frac{\mathrm{d} \ln E(y)}{\mathrm{d} \ln y}\right]_{y=\mu^{0}} .
$$

Using $y=\mu^{0}(s)$ in (14) and the equilibrium condition $E\left(\mu^{0}(s)\right)=s / 2$, one first computes

$$
\eta=\frac{\frac{\mathrm{d} \ln E\left(\mu^{0}(s)\right)}{\mathrm{d} \ln s}}{\frac{\mathrm{d} \ln \mu^{0}(s)}{\mathrm{d} \ln s}}=\frac{1}{\frac{\mathrm{d} \ln \mu^{0}(s)}{\mathrm{d} \ln s}} .
$$

Second, using (6) at equilibrium values, we have

$$
\frac{\mathrm{d} \ln \mu^{0}(s)}{\mathrm{d} \ln s}=\frac{s}{2 \mu^{0} E^{\prime}\left(\mu^{0}\right)} .
$$

The derivative $E^{\prime}\left(\mu^{0}\right)$ can be computed as to $\left(a_{H}-a_{L}\right) / \ell^{\prime}$ evaluated at $z^{0}$, the index of the good that makes individuals indifferent to any of its quality versions (i.e. solution of $\ell\left(z^{0}\right)=\mu^{0}$ ). Plugging in the two last expressions and reshuffling yields the simple formula

$$
\eta=\frac{2}{s}\left[\frac{z\left(a_{H}-a_{L}\right)}{\frac{d \ln \ell}{d \ln z}}\right]_{z=z^{0}}
$$

Corollary 1 implies that $\eta$ increases for higher cost between quality upgrades (larger $a_{H}-a_{L}$ ) and for flatter input-per-quality schedule ( $\operatorname{smaller} \mathrm{d} \ln \ell / \mathrm{d} \ln z$ ). That is, inputper-quality does not rise too fast as consumers decide to consume larger set of high quality goods. A stable trade equilibrium $(\eta>1)$ therefore requires sufficiently high costs of quality upgrades and/or low changes in input-per-quality.

\section{Appendix D: Equilibrium conditions with trade costs}

In this appendix, we establish the comparative statics around the symmetric trade equilibrium.

Totally differentiating (17) around the symmetric equilibrium $\left(s=s^{*}, m=1, w=\right.$ $1, \mu=\mu^{*}=\mu_{\tau}^{0}$ ) gives

$$
\begin{aligned}
\tilde{\mu}\left(\eta \phi+\eta_{\tau} \phi_{\tau}\right)-\widetilde{w}\left(\eta \phi+\phi_{\tau}\right) & =\widetilde{s}+\left(\eta_{\tau}-1\right) \tilde{\tau} \phi_{\tau} \\
\tilde{\mu}^{*}\left(\eta \phi+\eta_{\tau} \phi_{\tau}\right)-\left(\eta_{\tau}-1\right) \widetilde{w} \phi_{\tau} & =\left(\eta_{\tau}-1\right) \tilde{\tau} \phi_{\tau} \\
\tilde{\mu} \eta_{\tau}-\eta_{\tau} \tilde{\mu}^{*}+\widetilde{w}\left(\eta_{\tau}-1\right) & =-\tilde{m}
\end{aligned}
$$


where $\eta=\eta\left(\mu_{\tau}^{0}\right), \eta_{\tau}=\eta\left(\mu_{\tau}^{0} / \tau\right)$ and $\phi=E\left(\mu_{\tau}^{0}\right) /\left[E\left(\mu_{\tau}^{0}\right)+\tau E\left(\mu_{\tau}^{0} / \tau\right)\right]$ and $\phi_{\tau}=$ $1-\phi$. Solving for the small differences $\left(\tilde{w}, \tilde{\mu}, \widetilde{\mu}^{*}\right)$ gives

$$
\begin{aligned}
\tilde{w} & =-\frac{\xi}{\Phi} \tilde{m}-\frac{\eta_{\tau}}{\Phi} \tilde{s} \\
\tilde{\mu} & =-\frac{((\eta-1) \phi+1)}{\Phi} \tilde{m}+\frac{\eta\left(\eta_{\tau}-1\right) \phi}{\xi \Phi} \tilde{s}+\frac{\left(\eta_{\tau}-1\right) \phi_{\tau}}{\xi} \tilde{\tau} \\
\tilde{\mu}^{*} & =-\frac{\left(\eta_{\tau}-1\right) \phi_{\tau}}{\Phi} \tilde{m}-\frac{\eta_{\tau}\left(\eta_{\tau}-1\right) \phi_{\tau}}{\xi \Phi} \tilde{s}+\frac{\left(\eta_{\tau}-1\right) \phi_{\tau}}{\xi} \tilde{\tau}
\end{aligned}
$$

where $\Phi=\phi \eta\left(2 \eta_{\tau}-1\right)+\phi_{\tau} \eta_{\tau}$ and $\xi=\phi \eta+\phi_{\tau} \eta_{\tau}$. This gives

$$
\begin{aligned}
\tilde{\mu}-\tilde{w} & =\frac{\phi_{\tau}\left(\eta_{\tau}-1\right)}{\Phi} \tilde{m}+\frac{\eta\left(\eta_{\tau}-1\right) \phi+\eta_{\tau}\left(\phi \eta+\phi_{\tau} \eta_{\tau}\right)}{\xi \Phi} \widetilde{s}+\frac{\left(\eta_{\tau}-1\right) \phi_{\tau}}{\xi} \widetilde{\tau} \\
\tilde{\mu}-\tilde{\tau} & =-\frac{((\eta-1) \phi+1)}{\Phi} \tilde{m}+\frac{\eta\left(\eta_{\tau}-1\right) \phi}{\xi \Phi} \widetilde{s}-\left(\frac{\phi_{\tau}+\phi \eta}{\xi}\right) \widetilde{\tau} \\
\tilde{\mu}^{*}-\tilde{w}-\tilde{\tau} & =\frac{\phi_{\tau}+\phi \eta}{\Phi} \tilde{m}+\eta_{\tau} \frac{\left(\phi_{\tau}+\phi \eta\right)}{\xi \Phi} \widetilde{s}-\frac{\phi_{\tau}+\phi \eta}{\xi} \widetilde{\tau}
\end{aligned}
$$

This simplifies to the equations in the text.

\section{Appendix E: Stability condition with heterogeneous populations}

In this Appendix, we establih the stability condition with heterogeneous populations. We follow the same tâtonnement approach as in "Appendix C".

We first introduce the time dimension $t$ and consider the following motion equation system:

$$
\begin{aligned}
\frac{\mathrm{d} \tilde{\mu}_{k}}{\mathrm{~d} t} & =-\frac{\theta_{1}}{2 \eta_{k}}\left[2 \eta_{k} \tilde{\mu}_{k}-\left(1+\eta_{k}\right) \tilde{w}\right], \quad k \in\{1, \ldots, K\} \\
\frac{\mathrm{d} \tilde{\mu}_{l}^{*}}{\mathrm{~d} t} & =-\frac{\theta_{1}}{2 \eta_{l}}\left[2 \eta_{l} \tilde{\mu}_{l}^{*}-\left(\eta_{l}-1\right) \tilde{w}\right], \quad l \in\{1, \ldots, K\} \\
\frac{\mathrm{d} \tilde{w}}{\mathrm{~d} t} & =-\theta_{2}\left[\tilde{w}+\frac{\sum_{k} \varphi_{k} \eta_{k} \tilde{\mu}_{k}-\sum_{l} \varphi_{l} \eta_{l} \tilde{\mu}_{l}^{*}}{\sum_{l} \varphi_{l} \eta_{l}-1}\right]
\end{aligned}
$$

where $\theta_{1}$ and $\theta_{2} \in(0,1)$ are adjustment speed parameters with $\theta_{1}+\theta_{2}=1$. In this system, consumers react to budget imbalances and the relative price $w$ adjust according to the trade imbalances.

We denote by $\widetilde{\varepsilon}$ the $(2 K+1) \times 1$ vector of equilibrium variables $\left(\widetilde{\mu}, \tilde{\mu}^{*}, w\right)$. We define that a trade equilibrium $\widetilde{\varepsilon}^{0}$ is stable if any small deviations from it, $\widetilde{\varepsilon}^{1}$, lead back to $\widetilde{\varepsilon}^{0}$. The motion process writes as

$$
\frac{\mathrm{d} \widetilde{\varepsilon}}{\mathrm{d} t}=M \widetilde{\varepsilon}
$$


where $M$ is the $(2 K+1) \times(2 K+1)$ matrix

$$
M=\left[\begin{array}{ccccccc}
-\theta_{1} & 0 & \ldots & 0 & 0 & \ldots & \frac{\theta_{1}}{2}\left(\frac{\eta_{1}+1}{\eta_{1}}\right) \\
0 & -\theta_{1} & \ldots & 0 & 0 & \ldots & \frac{\theta_{1}}{2}\left(\frac{\eta_{2}+1}{\eta_{2}}\right) \\
\ldots & \ldots & \ldots & \ldots & \ldots & \ldots & \ldots \\
0 & 0 & \ldots & -\theta_{1} & 0 & \ldots & \frac{\theta_{1}}{2}\left(\frac{1-\eta_{1}}{\eta_{1}}\right) \\
0 & 0 & \ldots & 0 & -\theta_{1} & \ldots & \frac{\theta_{1}}{2}\left(\frac{1-\eta_{2}}{\eta_{2}}\right) \\
\ldots & \ldots & \ldots & \ldots & \ldots & \ldots & \ldots \\
-\theta_{2} \rho_{1} \eta_{1} & -\theta_{2} \rho_{2} \eta_{2} & \ldots & \theta_{2} \rho_{1} \eta_{1} & \theta_{2} \rho_{2} \eta_{2} & \ldots & -\theta_{2}
\end{array}\right]
$$

where

$$
\rho_{k}=\frac{\varphi_{k}}{-1+\sum_{l} \varphi_{l} \eta_{l}}
$$

The solution of this linear system of ordinary differential equations is given by $\widetilde{\varepsilon}=\widetilde{\varepsilon}^{1} e^{y t}$ where $y$ is an eigenvalue of $M$. The equilibrium is stable if it converges back to its initial value. The equilibrium is stable if and only if all $y$ have non positive real parts. The eigenvalues solves the characteristic polynomial $P(y)=\operatorname{det} M-y I=-P_{1}(y) P_{2}(y)$ where $P_{1}(y)=\left(y+\theta_{1}\right)^{2 K-1}$ and $P_{2}(y)=$ $y^{2}+y+\theta_{1} \theta_{2}\left(1+\sum_{k=1}^{K} \rho_{k} \eta_{k}\right)$. On the one hand, $P_{1}(y)$ has only negative roots. On the other hand, $P_{2}(y)$ has the same structure as the characteristic polynomial obtained for homogeneous populations $P(y)=\left[(\eta-1) y^{2}+y(\eta-1)+\eta \theta_{1} \theta_{2}\right]$. Its roots have the same property when one replaces $\eta /(\eta-1)$ by $1+\sum_{k=1}^{K} \rho_{k} \eta_{k}$, or equivalently substitutes $\eta$ by $1+\left(\sum_{k=1}^{K} \rho_{k} \eta_{k}\right)^{-1}$. Hence, all eigenvalues have negative real parts if and only if $1+\left(\sum_{k=1}^{K} \rho_{k} \eta_{k}\right)^{-1}>1$. That means, $\sum_{k=1}^{K} \rho_{k} \eta_{k}>0$ or, after simplifications, $\sum_{k=1}^{K} \varphi_{k} \eta_{k}>1$.

\section{Appendix F: Comparative statics with heterogeneous populations}

Here, we prove the results in Table 4. Comparative statics with respect to $\tilde{m}$ are trivially obtained from expressions (25-29). Comparative statics with respect to $\widetilde{s}_{k}\left(\widetilde{s}_{k}>0=\right.$ $\left.\tilde{s}_{j}, j \neq k\right)$ trivially yield $\mathrm{d} \widetilde{w} / \mathrm{d} \widetilde{s}_{k}<0, \mathrm{~d} \tilde{\mu}_{j} / \mathrm{d} \widetilde{s}_{k}<0$ and $\mathrm{d}\left(\tilde{\mu}_{l}^{*}-\widetilde{w}\right) / \mathrm{d} \widetilde{s}_{k}>0$. Also, one can check that $\mathrm{d} \tilde{\mu}_{l}^{*} / \mathrm{d} \widetilde{s}_{k}>0>\mathrm{d}\left(\widetilde{\mu}_{l}^{*}-\widetilde{w}\right) / \mathrm{d} \widetilde{s}_{k}$ if and only if $\eta_{l} \leq 1$. Care should be taken with the group $k$ that has higher productivity as we get

$$
\tilde{\mu}_{k}=\frac{1}{\eta_{k}} \widetilde{s}_{k}-\frac{\eta_{k}+1}{2 \eta_{k} \bar{\eta}} \varphi_{k} \widetilde{s}_{k}=\frac{1}{\eta_{k}} \widetilde{s}_{k}\left(1-\frac{\eta_{k}+1}{2 \sum_{l} \varphi_{l} \eta_{l}} \varphi_{k}\right)
$$




$$
\tilde{\mu}_{k}-\widetilde{w}=\frac{1}{\eta_{k}} \widetilde{s}_{k}+\frac{\eta_{k}-1}{2 \eta_{k} \bar{\eta}} \varphi_{k} \widetilde{s}_{k}=\frac{1}{\eta_{k}} \widetilde{s}_{k}\left(1+\frac{\eta_{k}-1}{2 \sum_{l} \varphi_{l} \eta_{l}} \varphi_{k}\right)
$$

Remind that Proposition 5 requires that $\sum_{l} \varphi_{l} \eta_{l}>1$. Reshuffling terms of the parenthesis in the first expression shows that it is positive if and only if

$$
\sum_{l \neq k} \varphi_{l} \eta_{l}+\sum_{l} \varphi_{l} \eta_{l}-\varphi_{k}>0
$$

This is true since the first term is larger than 0 , the second term larger than 1 and the last term larger than -1 since $\varphi_{k} \in(0,1)$. Hence, $\mathrm{d} \tilde{\mu}_{k} / \mathrm{d} \widetilde{s}_{k}>0$. Reshuffling terms of the parenthesis in the second expression shows that it is also positive if

$$
\sum_{l} \varphi_{l} \eta_{l}+\eta_{k} \varphi_{k}+\sum_{l} \varphi_{l} \eta_{l}-\varphi_{k}>0
$$

The two first terms are positive while the third term is larger than 1 and the last term larger than -1 since $\varphi_{k} \in(0,1)$. Thus, $\mathrm{d}\left(\tilde{\mu}_{k}-\widetilde{w}\right) / \mathrm{d} \widetilde{s}_{k}>0$.

\section{Appendix G: Proof of Proposition 6}

The results of the proposition related to specialization in high quality exports can be derived by checking Table 4 and its proof. First, we show that the domestic skill group $j$ is harmed by the productivity advantage of $k$ compared to its foreign counterpart. Begin by noting that $\widetilde{\mu}_{j}-\widetilde{w}>0>\widetilde{\mu}_{j}$. Hence, group $j$ purchases an additional mass of local high-quality goods, $v\left(\mu_{j}^{0}\right)\left(\tilde{\mu}_{j}-\widetilde{w}\right)$, and cuts its mass of high-quality imports by $v\left(\mu_{j}^{0}\right) \tilde{\mu}_{j}$ with $v=d \ln H / d \ln y$ defined in Sect. 3.2. In the end, group $j$ reduces the overall mass of its high-quality consumption by $v\left(\mu_{j}^{0}\right)|\widetilde{w}|$ where $|\cdot|$ is the absolute value operator. Group $j$ therefore unambiguously loses from group $k$ 's productivity advantage.

Second, we show that a higher productivity of skill group $k$ increases exports values in both directions. Indeed, the group $k$ 's impact on foreign import value can be read from the RHS of the trade balance condition (24), which writes as $\widetilde{w}+$ $\sum_{l} \varphi_{l} \eta_{l}\left(\tilde{\mu}_{l}^{*}-\widetilde{w}\right)$. Using (25) and (29), this simplifies to $\varphi_{k} \tilde{s}_{k}(\bar{\eta}-1) /(2 \bar{\eta})$, which is positive for $\widetilde{s}_{k}>0$ under the equilibrium stability condition $\bar{\eta}>1$ of Lemma 2 . Hence, a better productivity for any individual skill group boosts trade values in both directions.

We conclude the proof by showing that, unlike trade values, the numbers of highquality exports do not unambiguously rise and, consequently, specialization in high quality exports does not necessarily arise in both countries. The total number of domestic high-quality imports increases if and only if $\sum_{j=1}^{K} v\left(\mu_{j}^{0}\right) \tilde{\mu}_{j} g_{j}>0$. Using (26), 
this inequality can be restated as

$$
\frac{v\left(\mu_{k}^{0}\right) g_{k}}{\varphi_{k} \eta_{k}}>\sum_{j=1}^{K} \frac{\eta_{j}+1}{2 \bar{\eta}} \frac{v\left(\mu_{j}^{0}\right) g_{j}}{\eta_{j}}
$$

The inequality holds for very large group $k$ as it reduces to $\eta_{k} \geq 1$ when $g_{k} \rightarrow 1$. More generally, for this inequality to hold, it must be that, compared to other local groups $j \neq k$, group $k$ has a larger share of population $g_{k}$, smaller share of labor supply $\varphi_{k}$, lower elasticity of real expenditure $\eta_{k}$ and higher consumption elasticity of highquality goods $v\left(\mu_{k}^{0}\right)$. Ceteris paribus, a larger share of group $k$ 's population indeed leads to more demand for high-quality imports. A smaller share in labor supply $\varphi_{k}$ implies smaller adverse changes in relative prices. However, note that the combination of high population share and low labor supply share is more easily obtained from low skilled than high skilled workers. Accordingly, one may expect a failure of the above condition when group $k$ refers to high skill communities.

\section{References}

Acemoglu, D.: Technical change, inequality, and the labor market. J. Econ. Lit. 40, 7-72 (2002)

Acemoglu, D.: Patterns of skill premia. Rev. Econ. Stud. 70, 199-230 (2003)

Acemoglu, D., Autor, D.: Skills, tasks and technologies: Implications for employment and earnings. Handb. Lab. Econ. 4, 1043-1171 (2011)

Amano, A.: Stability conditions in the pure theory of international trade: a rehabilitation of the Marshallian approach. Q. J. Econ. 82, 326-339 (1968)

Amiti, M., Khandelwal, A.K.: Import competition and quality upgrading. Rev. Econ. Stat. 95, 476-490 (2013)

Arkolakis, C., Costinot, A., Donaldson, D., Rodríguez-Clare, A.: The elusive pro-competitive effects of trade. Rev. Econ. Stud. 86, 46-80 (2019)

Armington, P.S.: A theory of demand for products distinguished by place of production. IMF Staff Pap. 16(1), 159-178 (1969)

Autor, D.H., Levy, F., Murnane, R.J.: The skill content of recent technological change: an empirical exploration. Q. J. Econ. 116(4), 1279-1333 (2003)

Behrens, K., Murata, Y.: General equilibrium models of monopolistic competition: a new approach. J. Econ. Theory 136, 776-787 (2007)

Behrens, K., Murata, Y.: Trade, competition, and efficiency. J. Int. Econ. 87, 1-17 (2012)

Behrens, K., Mion, G., Murata, Y., Südekum, J.: Trade, wages and productivity. Int. Econ. Rev. 55, 13051348 (2014)

Berman, E., Bound, J., Griliches, Z.: Changes in the demand for skilled labor within U.S. manufacturing industries: evidence from the Annual Survey of Manufactures. Q. J. Econ. 109, 365-67 (1994)

Berman, E., Bound, J., Machin, S.: Implications of skill-biased technological change: international evidence. Q. J. Econ. 113, 1245-1279 (1998)

Bertoletti, P., Etro, F.: Preferences, entry and market structure. Rand J. Econ. 47, 792-821 (2016)

Bertoletti, P., Etro, F.: Monopolistic competition when income matters. Econ. J. 127, 1217-1243 (2017)

Bertoletti, P., Etro, F., Simonovska, I.: International trade with indirect additivity. Am. Econ. J. Microecon. 10, 1-57 (2018)

Bond, E.W., Iwasa, K., Nishimura, K.: A dynamic two country Heckscher-Ohlin model with non-homothetic preferences. Econ. Theory 48, 171-204 (2011). https://doi.org/10.1007/s00199-010-0572-8

Boom, A.: Asymmetric international minimum quality standards and vertical differentiation. J. Ind. Econ. 43, 101-19 (1995)

Caves, R.E., Frankel, J.A., Jones, R.W.: World Trade and Payments: An Introduction. Addison-Wesley, New-York (2002) 
Cho, S.-W.S., Díaz, J.P.: Skill premium divergence: the roles of trade, capital and demographics. Econ. Theory 67, 249-283 (2019). https://doi.org/10.23656/25045520/012018/0152

Crampes, C., Hollander, A.: Duopoly and quality standards. Eur. Econ. Rev. 39, 71-82 (1995)

Crozet, M., Head, K., Mayer, T.: Quality sorting and trade: firm-level evidence for French wine. Rev. Econ. Stud. 79(2), 609-644 (2012)

de Lucio Fernández, J.J., Mínguez, R., Minondo, A., Requena, F.: The Variation of Export Prices Across and Within Firms. Mimeo, New York (2016)

Di Comite, F., Thisse, J.-F., Vandenbussche, H.: Verti-zontal differentiation in export markets. J. Int. Econ. 93(1), 50-66 (2014)

Dingel, J.: The determinants of quality specialization. Rev. Econ. Stud. 84, 1551-1582 (2017)

Dhingra, S., Morrow, J.: Monopolistic competition and optimum product diversity under firm heterogeneity. J. Polit. Econ. 127, 196-232 (2019)

Dornbusch, R., Fischer, S., Samuelson, P.A.: Comparative advantage, trade, and payments in a Ricardian model with a continuum of goods. Am. Econ. Rev. 67, 823-839 (1977)

Eaton, J., Fieler, A.C.: The gravity of unit values. Soc. Econ. Dyn. Work. Pap. 1639, 225-230 (2017)

Ecchia, G., Lambertini, L.: Minimum quality standards and collusion. J. Ind. Econ. 45, 101-13 (1997)

Fajgelbaum, P., Grossman, G.M., Helpman, E.: Income distribution, product quality, and international trade. J. Polit. Econ. 119, 721-65 (2011)

Fajgelbaum, P., Grossman, G.M., Helpman, E.: A Linder-hypothesis for foreign direct investment. Rev. Econ. Stud. 82, 83-121 (2015)

Fan, H., Li, Y.A., Yeaple, S.R.: Trade liberalization, quality and export prices. Rev. Econ. Stat. 97, 1033$1051(2015)$

Feenstra, R.C., Romalis, J.: International prices and product quality. Q. J. Econ. 129, 477-527 (2014)

Fieler, A.C.: Quality differentiation in international trade: theory and evidence. Working paper, University of Pensylvania (2012)

Flam, H., Helpman, E.: Vertical product differentiation and north-south trade. Am. Econ. Rev. 77, 810-822 (1987)

Foellmi, R., Hepenstrick, C., Zweimüller, J.: International arbitrage and the extensive margin of trade between rich and poor countries. Rev. Econ. Stud. 85, 475-510 (2018)

Foellmi, R., Zweimueller, J.: Income distribution and demand-induced innovations. Rev. Econ. Stud. 73, 941-960 (2006)

Fontaine, F., Martin, J., Mejean, I.: Price discrimination within and across EMU markets: Evidence from French exporters. J. Int. Econ. 142, 103300 (2020)

Gabszewicz, J., Thisse, J.-F.: Price competition, quality and income distribution. J. Econ. Theory 20, 340359 (1979)

Gabszewicz, J., Wauthy, X.J.: The option of joint purchase in vertically differentiated markets. Econ. Theory 22, 817-829 (2003). https://doi.org/10.1007/s00199-003-0359-2

Goldin, C., Katz, L.F.: The origins of technology-skill complementarity. Q. J. Econ. 113, 693-732 (1998)

Hallak, J.C., Schott, P.K.: Estimating cross-country differences in product quality. Q. J. Econ. 126, 417-474 (2011)

Hummels, D., Klenow, P.J.: The variety and quality of a nation's exports-. Am. Econ. Rev. 95, 704-723 (2005)

Iacovone, L., Javorcik, B.S.: Multi-product exporters: product churning, uncertainty and export discoveries. Econ. J. 120, 481-499 (2010)

Jaimovich, E.: Quality growth: from process to product innovation along the path of development. Econ. Theory (2020). https://doi.org/10.1007/s00199-020-01266-0

Jaimovich, E., Merella, V.: Quality ladders in a Ricardian model of trade with nonhomothetic preferences. J. Eur. Econ. Assoc. 10, 908-937 (2012)

Jaimovich, E., Merella, V.: Love for quality, comparative advantage, and trade. J. Int. Econ. 97, 376-391 (2015)

Khandelwal, A.: The long and short (of) quality ladders. Rev. Econ. Stud. 77(4), 1450-1476 (2010)

Krugman, P.R.: Intraindustry specialization and the gains from trade. J. Polit. Econ. 89, 959-973 (1981)

Lai, E.L.-C., Fan, H., Qi, H.S.: Global gains from reduction in trade costs. Econ. Theory 70, 313-345 (2020). https://doi.org/10.1007/s00199-019-01190-y

Linder, S.: An Essay on Trade and Transformation. Almqvist and Wiksell, Stockholm (1961)

Machin, S., Van Reenen, J.: Technology and changes in skill structure: evidence from seven OECD countries. Q. J. Econ. 113, 1215-1244 (1998) 
Marshall, A.: The Pure Theory of Foreign Trade, 19493 edn. The London School of Economics and Political Science, London (1879)

Matsuyama, K.: The home market effect and patterns of trade between rich and poor countries. CFM DP 2015-19 (2015)

Matsuyama, K.: Engel's law in the global economy: demand-induced patterns of structural change, innovation, and trade. Econometrica 87, 497-528 (2018)

Matsuyama, K.: A Ricardian model with a continuum of goods under nonhomothetic preferences: demand complementarities, income distribution, and north-South trade. J. Polit. Econ. 108, 1093-1120 (2000)

Markusen, J.R.: Putting per-capita income back into trade theory. J Int. Econ. 90, 255-265 (2013)

Maxwell, J.W.: Minimum quality standards as a barrier to innovation. Econ. Lett. 58, 355-60 (1998)

Melitz, M.: The impact of trade on intra-industry reallocations and aggregate industry productivity. Econometrica 71, 1695-1725 (2003)

Mussa, M., Rosen, S.: Monopoly and product quality. J. Econ. Theory 18, 301-317 (1978)

Parenti, M., Ushchev, P., Thisse, J.-F.: Toward a theory of monopolistic competition. J. Econ. Theory 167, 86-115 (2017)

Picard, P.M., Okubo, T.: Firms' locations under demand heterogeneity. Reg. Sci. Urban Econ. 42(6), 961974 (2012)

Picard, P.M., Tampieri, A.: Trade, vertical differentiation and the quality margin, Working Papers - Economics 03 Università degli Studi di Firenze, Dipartimento di Scienze per l'Economia e 1'Impresa (2019)

Picard, P.M., Tampieri, A.: Income effects and vertical differentiation in international trade, CORE Discussion Papers 2016023. Université catholique de Louvain, Center for Operations Research and Econometrics (CORE) (2016)

Ratts $\varnothing$, J., Stokke, H.E.: Trade, skill biased technical change and wage inequality in South Africa. Rev. Int. Econ. 21, 419-431 (2013)

Sauré, P.: Bounded love for variety and patterns of trade. Open Econ. Rev. 23, 645-674 (2012)

Schott, P.K.: Across-product versus within-product specialization in international trade. Q. J. Econ. 119, 647-678 (2004)

Simonovska, I.: Income differences and prices of tradables: insights from an online retailer. Rev. Econ. Stud. 82, 1612-1656 (2015)

Shaked, A., Sutton, J.: Relaxing price competition through product differentiation. Rev. Econ. Stud. 49, 3-13 (1982)

Stokey, N.: The volume and composition of trade between rich and poor countries. Rev. Econ. Stud. 58, 63-80 (1991)

Tanaka, Y.: Profitability of price and quantity strategies in a duopoly with vertical product differentiation. Econ. Theory 17, 693-700 (2001). https://doi.org/10.1007/PL00004124

Tarasov, A.: Income distribution, market structure, and individual welfare. B.E. J. Theor. Econ. 9(1), 1-39 (2009)

Tarasov, A.: Trade liberalization and welfare inequality: a demand-based approach. Scand. J. Econ. 114(4), 1296-1317 (2012)

Verhoogen, E.: Trade, quality upgrading and wage inequality in the Mexican manufacturing sector. Q. J. Econ. 123, 489-530 (2008)

Wang, X.H.: A note on the high-quality advantage in vertical differentiation models. Bull. Econ. Res. 55, 91-9 (2003)

Wood, A.: North-South Trade, Employment and Inequality: Changing Forms in a SkillDriven World. Clarendon Press, Oxford (1995)

Zhelobodko, E., Kokovin, S., Parenti, M., Thisse, J.-F.: Monopolistic competition: beyond CES. Econometrica 80, 2765-2784 (2012)

Publisher's Note Springer Nature remains neutral with regard to jurisdictional claims in published maps and institutional affiliations. 